\title{
Availability of High Quality TRMM Ground Validation Data from Kwajalein, RMI: A Practical Application of the Relative Calibration Adjustment Technique
}

\author{
David A. Marks ${ }^{1,2}$, David B. Wolff ${ }^{1,2}$, David S. Silberstein ${ }^{1,2}$, Ali Tokay ${ }^{1,3}$, \\ Jason L. Pippitt ${ }^{1,2}$, and Jianxin Wang ${ }^{1,2}$ \\ ${ }^{1}$ NASA Goddard Space Flight Center, Laboratory for Atmospheres, Greenbelt, Maryland \\ ${ }^{2}$ Science Systems and Applications, Inc., Lanham, Maryland \\ ${ }^{3}$ Joint Center for Earth Systems Technology, University of Maryland, Baltimore County
}

Submitted to

Journal of Atmospheric and Oceanic Technology

May 2008

Corresponding author address

David A. Marks

SSAI@NASA/GSFC, Code 613.1

Greenbelt, MD 20771

David.A.Marks@nasa.gov 


\begin{abstract}
Since the Tropical Rainfall Measuring Mission (TRMM) satellite launch in November 1997, the TRMM Satellite Validation Office (TSVO) at NASA Goddard Space Flight Center (GSFC) has been performing quality control and estimating rainfall from the KPOL S-band radar at Kwajalein, Republic of the Marshall Islands. Over this period, KPOL has incurred many episodes of calibration and antenna pointing angle uncertainty. To address these issues, the TSVO has applied the Relative Calibration Adjustment (RCA) technique to eight years of KPOL radar data to produce Ground Validation (GV) Version 7 products. This application has significantly improved stability in KPOL reflectivity distributions needed for Probability Matching Method (PMM) rain rate estimation and for comparisons to the TRMM Precipitation Radar (PR). In years with significant calibration and angle corrections, the statistical improvement in PMM distributions is dramatic. The intent of this paper is to show improved stability in corrected KPOL reflectivity distributions by using the PR as a stable reference. Intermonth fluctuations in mean reflectivity differences between the PR and corrected KPOL are on the order of $\pm 1-2 \mathrm{~dB}$, and inter-year mean reflectivity differences fluctuate by approximately \pm 1 dB. This represents a marked improvement in stability with confidence comparable to the established calibration and uncertainty boundaries of the PR. The practical application of the RCA method has salvaged eight years of radar data that would have otherwise been unusable, and has made possible a high-quality database of tropical ocean-based reflectivity measurements and precipitation estimates for the research community.
\end{abstract}




\section{Introduction}

There are many applications where quantitative rainfall estimation is essential. From station climatology to validation of satellite algorithms, the estimation of rainfall using ground-based radar is a necessity. A stable and well-calibrated radar is an absolute requirement for robust rainfall estimation (Ulbrich and Lee, 1999). This is certainly true in tropical oceanic regions where rain gauge measurements are sparse, and polar orbiting satellite overpass revisit times are less frequent than at higher latitudes. The Kwajalein oceanic region in the Republic of the Marshall Islands (Figure 1) is one of several unique GV locations for TRMM validation studies (Schumacher and Houze 2000, Houze et al. 2004, Wolff et al. 2005, Yuter et al. 2005), mesoscale and physical characterization studies (Sobel et al. 2004, Cetrone and Houze 2006, Holder et al. 2008), cloud-resolving model simulations (Blossey et al. 2007), and other research topics. The NASA supported KPOL S-band weather radar located on Kwajalein Island $\left(8.7^{\circ} \mathrm{N}\right.$, $167.7^{\circ} \mathrm{E}$ ) is a vital tool in these efforts. KPOL task configurations are shown in Table 1, and additional radar characteristics are found in Schumacher and Houze, 2000 (their Table 1), and Wolff et al. 2005 (their Table 1). The virtually complete oceanic coverage in this remote location makes data from the Kwajalein GV site highly desirable, however technical and logistical concerns have often pushed data quality issues to the forefront. Concerns regarding KPOL calibration and overall stability have repeatedly compromised attempts to provide

accurate and consistent reflectivity measurements and rain rate estimates. KPOL radar sensitivity has fluctuated for a variety of reasons including mechanical and engineering issues (e.g. failed parts in harsh environmental conditions), software instability, abrupt power adjustments, and antenna pointing angle changes. It became obvious that a method was needed to first detect these changes, and then quantify the impact on the data itself before useful 
validation products could be provided. The Relative Calibration Adjustment (RCA) and monitoring technique (Silberstein et al. 2008 - hereafter S08) detects and quantifies radar sensitivity changes to within accuracy of $\pm 0.5 \mathrm{~dB}$. In the practical application of RCA theory, ensemble KPOL data from locations with persistent ground clutter signatures are objectively analyzed to routinely detect, monitor, and quantify radar sensitivity fluctuations, antenna elevation changes, and overall KPOL status in a near real-time operational environment. The scope of this paper is to a) describe frequently encountered KPOL radar and data issues; b) explain historical data correction attempts and limitations; c) examine the practical application of RCA theory; d) provide a comparison between RCA and other correction methods; and e) quantitatively show the significantly improved stability of the corrected radar data and resulting statistical consistency from WPMM (Rosenfeld et al. 1994) in reflectivity - rain rate relation development.

\section{Frequently encountered issues and historical TSVO correction attempts a. Early TSVO processing}

The KPOL radar has a long history of problems that have run the gamut from hardware and software failure to unplanned or undocumented antenna elevation angle changes. From 2000 through 2007, KPOL's performance has been dominated by time periods of relative stability punctuated by sharp sensitivity (power calibration) and elevation angle changes. KPOL radar sensitivity has changed frequently and for various reasons as shown in Houze et al. 2004 (their Table 2). Mechanical and engineering issues such as waveguide pressurization leaks with subsequent arcing, replacement of directional couplers with suspected incomplete follow-through procedures, pulse-forming network replacements, elevation and azimuth drive motor failures, unexplained antenna gain changes, and general calibration drift have all occurred within the 
extremely harsh environmental conditions that define this region. Elevation angle changes have been caused by a suspected faulty electrical panel with spliced connections, and the use of a problematic release of a solar tracking utility.

Historical attempts to quantify the effect of sensitivity/calibration changes have shown only modest success. Because limited engineering documentation was available from KPOL, early versions of the TSVO products (through Version 4) concentrated more on adjusting reflectivity to match rain gauge rainfall rates rather than correcting the reflectivity field itself. These versions used the "bulk-adjustment" technique to force agreement between radar reflectivity and rain gauge measurements (Marks et al. 2000, Amitai et al. 2006). As explained in Amitai et al. 2006, guidelines from the prelaunch TRMM GV Science Team specified the use of rain gaugeadjusted power-law relations of the form

$$
Z_{e}=A R^{b}
$$

with fixed exponent $\mathrm{b}=1.4$. In this context, $Z_{e}$ is the effective (or observed) reflectivity ${ }^{1}$. A network of quality controlled gauges was used to tune the power-law coefficient A such that total monthly rainfall, as estimated from the radar $Z_{e}$ pixels above the gauges, was matched to the combined gauge accumulations ( $\mathrm{G})$ :

$$
A=\left[\sum\left(Z_{e}^{1 / b}\right) / \sum G\right]^{b} .
$$

Rain gauge data were interpolated and quality-controlled via a cubic spline-based method described in Wang et al. 2008. Separate monthly convective and stratiform $Z_{e}-R$ relations were generated using the reflectivity classification criteria defined in Steiner et al. (1995). Within the KPOL field of view, there are only 15 rain gauge sites. Seven locations are shown in Wolff et al 2005, and the additional eight comprise the "X-array" at Roi-Namur island (approximately 80 
$\mathrm{km}$ north of the KPOL site). Data from six of the X-array gauges became available in April 2003, and the additional two in April 2005. By the bulk-adjustment method, known and unknown radar calibration adjustments were incorporated into radar estimated rain rates, but the TRMM Standard Products (TSP) 1C-51 and 2A-55 (see Wolff et al. 2005 Table 4 for product descriptions) did not contain calibration corrected reflectivity. The resulting wide variations in $Z_{e}-R$ relationships (in-house study) clearly showed that egregious inconsistencies existed between observed reflectivity and gauge rain rates.

\section{b. TSVO Version 5 processing}

In the progression to TSVO Version 5 validation products, the monthly bulk-adjustment and power-law method was abandoned in favor of WPMM to statistically match radar and rain gauge data for derivation of $Z_{e}-R$ lookup tables. In order to obtain sufficient sample sizes for WPMM, monthly observations of radar and rain gauge pairs were combined for an entire year without regard to classification. The official (operational) Version 5 products for Kwajalein used a fixed WPMM derived $Z_{e}-R$ lookup table (derived from year 2002 reflectivity and rain gauge data) for rain rate estimation, but still had no reflectivity calibration adjustments (Wolff et al. 2005). Reflectivity distributions for WPMM were from a SPRINT interpolated (Mohr and Vaughan, 1979) constant altitude plan-position indicator (CAPPI) level of $1.5 \mathrm{~km}$, and the rain gauge data were interpolated and quality-controlled via the cubic spline-based method described in Wang et al. 2008. Based on available KPOL engineering information that implied reflectivity from year 2002 was very stable, the entire year of data was chosen for development of an operational WPMM $Z_{e}-R$ table. However, essential to this study's comparison to later product versions (6 and 7), separate yearly WPMM $Z_{e}-R$ lookup tables were generated from years 2000 through 2007. While the WPMM does not require certainty in the absolute calibration of the radar, it 
definitely requires stability in the relative calibration. Statistical inconsistencies develop if the relative radar calibration is absent. Figure 2 shows the divergence in yearly $Z_{e}-R$ lookup tables from the Version 5 methodology, and Table 2 shows the associated approximate power-law A coefficients derived for each year. (Note: Version 6 and 7 coefficients in Table 2 are discussed in section $3 b$ ). The diverging curves and coefficients indicate distinctly different inter-annual WPMM reflectivity distributions. We believe these differences lack a physical rationale.

Disdrometer studies indicate that reflectivity distributions in the Kwajalein climatic regime show very little variation in both temporal and spatial scales (Schumacher and Houze, 2000; Tokay et al. 2008a). The north-south oscillation of the inter-tropical convergence zone (ITCZ) primarily dominates the precipitation for the entire region. Employing two years of disdrometer observations in Kwajalein, the composite raindrop spectra were constructed at the $40 \mathrm{dBZ}$ interval $( \pm 0.5 \mathrm{~dB})$ for four different rain events (Figure 3a). The disdrometer was an impact type (Joss and Waldvogel 1967) and the reflectivity was calculated from one-minute disdrometer observations. We intentionally selected the $40 \mathrm{dBZ}$ interval, below which the size spectra are narrow in the absence of large drops and where intra-storm variability (e.g. convective versus stratiform rainfall) may occur, and above which the sample size is very limited (less than 5 oneminute observations). The agreement in composite spectra between the different events is evident. The presence of high concentrations of small drops and low concentrations of large drops resulted in higher total number of concentrations, liquid water content, and rain rate than extratropical cyclones (Tokay et al. 2008b). All three integral parameters that were shown in Figure $3 a$ were calculated from observed spectra. We repeated the same exercise employing one year of Roi-Namur disdrometer observations. Figure $3 \mathrm{~b}$ shows the composite spectra at $40 \mathrm{dBZ}$ from three different events. Again, the agreement in composite spectra between the events as 
well as between the Kwajalein and Roi-Namur locations is evident. This suggests that for a given reflectivity, one should expect a very narrow range of rain rate and therefore a single $Z_{e^{-}} R$ relation may be relevant in the absence of inter-storm variability.

The year-to-year reflectivity distribution differences of Version 5 shown in Figure 2 and Table 2 indicate probable instability in relative radar calibration. To quantify the yearly variation in Version 5 reflectivity distributions, we compared the mean reflectivity with a recognized stable standard, the TRMM Precipitation Radar (PR). It has been demonstrated that the TRMM PR is consistent in calibration stability (with large signal-to-noise (S/N) ratio) to within $0.8 \mathrm{~dB}$ (Kozu et al. 2001), and with estimated uncertainty in reflectivity factor less than $1.0 \mathrm{~dB}$ (Kummerow et al. 1998, Iguchi et al. 2000). This level of stability provides a reference to quantify the resultant instability of the TSVO KPOL Version 5 reflectivity. TSP 2A-55 (Wolff et al. 2005 - their Table 4) is a three-dimensional Cartesian gridded (via SPRINT - Mohr and Vaughan, 1979) quality-controlled reflectivity product with resolution of 151 x 151 x 13 pixels (2 km x $2 \mathrm{~km}$ horizontal, $1.5 \mathrm{~km}$ vertical, with 13 constant altitude PPI (CAPPI) height levels). Mean attenuation corrected reflectivities from PR 2A25 Version 6 were compared with mean ground radar reflectivities from KPOL 2A55 Version 5. For this comparison, both KPOL and PR reflectivity data were resampled to a three-dimensional Cartesian grid with $4 \mathrm{~km} \mathrm{x} 4 \mathrm{~km}$ horizontal and $1.5 \mathrm{~km}$ vertical resolution. The Cartesian origin was centered at the KPOL site with horizontal extent of $150 \mathrm{~km}$ and vertical range from 0 to $20 \mathrm{~km}$. Only data classified as stratiform were included, where classification was obtained by the 2 A23 algorithm for the PR (Awaka et al. 1997), and the 2A54 algorithm for KPOL (Steiner et al. 1995). These comparisons used data $\geq 18 \mathrm{dBZ}$ to be above the PR sensitivity threshold, from multiple heights to minimize uncertainties associated with sampling resolutions, and within eight-minute time windows of the 
PR scan time (-1 minute $\leq\left[\mathrm{PR}_{\text {time }}-\mathrm{KPOL}_{\text {time }}\right] \leq+7$ minutes $)$. This was a direct comparison of mean reflectivity measurements at multiple levels from both instruments, and is similar to the method of Anagnostou et al. (2001) - (hereafter referred to as A01). There are numerous sources of error when comparing reflectivity from space-based with ground-based radar (Bolen and Chandrasekar, 2000; Bolen and Chandrasekar, 2003). These include consideration for different view angles, beamwidths, frequencies, noise floor, hydrometeor distribution, time synchronization mismatch, and interpolation error, among others. Bolen and Chandrasekar (2000) performed a theoretical comparison of reflectivity at $\mathrm{S}$ and $\mathrm{Ku}$ bands (assuming no relative calibration bias between the radars) and showed that theoretical reflectivity differences ( $\mathrm{S}$ band $-\mathrm{K}$ band) could range from $\pm 0.5 \mathrm{~dB}$ within bounds of one standard deviation. To complement that study, Bolen and Chandrasekar (2003) developed a method to align and compare spaceborne and ground-based radar observations with emphasis on volume matching and geometric corrections. Application of their method to data from the TEFLUN-B field campaign (August 1998) with the NCAR-SPOL radar, and KPOL data from July 2000 showed that their method minimizes spaceborne and ground-based comparison errors, however proper calibration of the ground-based radar is of crucial importance. Measurement uncertainty in the PR reflectivity is approximately $1 \mathrm{~dB}$, while uncertainty in the uncalibrated and unstable Version 5 KPOL reflectivity measurements is a significant variable. Indeed, KPOL calibration was low by approximately $6 \mathrm{~dB}$ (as compared to the PR) at the start of the KWAJEX field campaign (Yuter et al. 2005), and has fluctuated significantly since then, (discussed in the following section), therefore we expected high standard deviations about the mean differences between the instruments. Version 5 comparison results showed inter-year (2000-2007) standard deviations about the mean differences in reflectivity ranging from $3.5 \mathrm{~dB}$ to $4.3 \mathrm{~dB}$. If the KPOL radar 
calibration had been stable, we would in theory expect measurement error of approximately \pm 1 dB. Combined with the uncertainty of the PR, the expected error associated with this type of comparison is approximately $\pm 2 \mathrm{~dB}$. The fluctuation of the mean differences between instruments is much more important to this study than the absolute magnitude of the differences themselves, because it is this fluctuation that quantifies the degree of instability in Version 5 reflectivity. The multiple panels of Figure 4 show monthly and yearly mean reflectivity differences (offsets) between TRMM PR 2A25 Version 6 and KPOL 2A55 Version 5 for rainy overpasses from years 2000 through 2007, and indicate years of both relative stability and extreme instability. Monthly fluctuations in mean reflectivity differences over the eight years are quite evident and are on the order of several dB, especially in years 2000, 2001, and 2003. In contrast, mean differences show very little fluctuation from May through December 2004. Months with no information represent periods where the KPOL radar was extremely unstable, and have therefore been removed. Data from August through December 2005 were removed due to multiple cascading KPOL component failures. The wide variation in reflectivity distributions is also reflected in the yearly mean differences shown in the final column in each yearly panel, and is on the order of $\pm 2 \mathrm{~dB}$. On the yearly scale there are thousands of $4 \mathrm{~km} \times 4 \mathrm{~km}$ pixels being compared; ranging from about 13,000 in year 2005, to more than 60,000 in year 2002 . The $95 \%$ confidence interval $(95 \% \mathrm{CI})$ of the yearly mean differences (to two significant figures) is nearly 0.0. The 95\% CI is derived from construction of a Student's t-test statistic (Wilks 1995)

$$
95 \% C I=\left(\bar{O}-t_{\alpha / 2} \frac{s}{\sqrt{n}}, \bar{O}+t_{\alpha / 2} \frac{s}{\sqrt{n}}\right)
$$

where $\bar{O}=\frac{1}{n} \sum_{n}\left(R_{P R}-R_{K P O L}\right)$, is the statistical significance level of $5 \%, t_{/ 2}$ is the $100(/ 2)$ th percentile of the t-distribution with n- 1 degrees of freedom, $s$ is the sample standard deviation of 
the individual offset $(\mathrm{O})$ values, and $n$ is the sample size where both $R_{P R}$ and $R_{K P O L} \geq 18 \mathrm{dBZ}$. The sample sizes on the monthly scale can be significantly smaller in the dry season of each year (January through March) where precipitation is mainly dominated by isolated to scattered showers. This is shown in Figure 4 by extreme fluctuations in mean differences, and lower confidence levels (larger 95\%CI bounds) in these three months. The level of instability shown in Version 5 reflectivity statistics and $Z_{e}-R$ curve divergence is unacceptable for consistent rain rate estimation. A technique to identify, quantify, and monitor relative calibration changes to radar reflectivity over persistent ground clutter areas was developed by the TSVO to provide the required stability.

\section{Relative Calibration Adjustment (RCA) theory and practical application a. RCA theory}

Unlike studies using a single source of continuous ground clutter (Rinehart 1978), the RCA technique uses a statistical ensemble of reflectivity values $\left(Z_{e}\right.$ in dBZ) from persistent ground clutter areas from every volume scan to monitor hourly and daily radar sensitivity changes. As detailed in S08, the $95^{\text {th }}$ percentile of the clutter area reflectivity distribution at the lowest elevation scan has been found to be remarkably stable from hour to hour, day to day, and month to month to within $\pm 0.5 \mathrm{~dB}$. It varies significantly only after deliberate system modifications, equipment failure, or other causes, some of which may be unknown. Selecting the $95^{\text {th }}$ percentile of the cumulative distribution function (CDF) associated with intense clutter reflectivities permits monitoring of radar stability (S08). This is because almost all precipitation

echoes are below the $95^{\text {th }}$ percentile level. Any transient rain echoes that approach the $95^{\text {th }}$ percentile reflectivity level are statistically insignificant on an hourly or daily basis relative to the 
ground clutter. The definition of a Relative Calibration Adjustment is the amount (in $\mathrm{dB}$ ) needed to force agreement between the $95^{\text {th }}$ percentile reflectivity distribution and the established calibration baseline. The reflectivity level at which the CDF attained 95\% defined our initial reference (baseline), and was determined in part by consensus of engineers and researchers from the University of Washington (UW), NASA, and Colorado State University (CSU) with data from the KWAJEX field campaign (Yuter et al. 2005). The original uncalibrated $95^{\text {th }}$ percentile reflectivity distribution value on 1 Aug 1999 was $44 \mathrm{dBZ}$. As explained in section 4, a calibration adjustment of $+6 \mathrm{~dB}$ was required. This brought the initial calibrated baseline to 50 dBZ. As described in S08, the ability of the RCA method to detect changes in radar sensitivity was validated (with KPOL operator assistance) and showed a direct one-to-one correspondence between KPOL calibration offset changes and ensemble $95^{\text {th }}$ percentile reflectivity distributions.

Probability and cumulative distribution functions (PDFs and CDFs) of reflectivity over the ensemble clutter locations are obtained on an hourly and daily basis to determine an RCA value, and include both the precipitation and clutter echoes. Figure 5 is a three-panel plot showing the hourly and daily PDF and CDF plots of clutter area reflectivity from a stable calibration day, a problem calibration day, and an antenna elevation irregularity day. Figure 5a (stable calibration) has hour-to-hour RCA fluctuations less than $0.5 \mathrm{~dB}$, and the calibration stability is graphically shown by the convergence in reflectivity distributions at the $95^{\text {th }}$ percentile (approximately 50 dBZ). The distribution spread below this level is the result of light precipitation echo and variations in the clutter field. Figure $5 \mathrm{~b}$ (problem calibration day) has a significant jump ( $>5$ $\mathrm{dB}$ ) in the hourly RCA values between 01 UTC and 03 UTC. Not enough data points were available for a valid distribution during the 02 UTC hour (therefore the -99.99 flag). Divergence in the $95^{\text {th }}$ percentile hourly reflectivity distributions is clearly evident in both the PDF and CDF 
analysis, and signifies that a sensitivity change has occurred. Review of engineering logs and correspondence with radar operators confirmed that a directional coupler had been swapped during the 02 UTC hour, and that calibration follow-through procedures were not completed, thereby affecting the calibration. Figure 5c (antenna elevation irregularity day) shows a significant fluctuation ( $>4 \mathrm{~dB}$ ) in the RCA value from the 22 UTC to 23 UTC hour. There were no known engineering issues affecting power on this day, so it was suspected that the antenna elevation angle had changed for an unknown reason. A different type of analysis was needed to diagnose the possible antenna elevation problem.

When attempting to diagnose radar elevation angle irregularities, a very useful method is to rank individual gate returns in order of descending reflectivity. In a nominal, stable configuration, the most intense reflectivity values will be situated across a range of distances encompassing points both near and far from the radar. However, if the radar elevation angle deviates from its typical orientation, the distances at which the most intense reflectivities are found vary significantly. In the case of a higher than normal elevation angle, the most intense points tend to cluster within a few kilometers of the radar, as targets at farther range are missed due to beam overshoot. In the case of a lower than normal elevation angle, the location of the most intense reflectivities tends to be at greater distances from the radar than the nominal case as more distant targets are captured within the radar beam. While this method tends to work best for more severe angular deviations on the order of several tenths of a degree, it is possible to detect even subtle angular change as the targets at Kwajalein are basically fixed and just a slight offset in antenna elevation will alter the rankings of the most intense reflectivities. In this particular case from 24 October 2007 (Figure 5 panel c), the RCA value increased by approximately $+4 \mathrm{~dB}$ between the $22 \mathrm{UTC}$ and $23 \mathrm{UTC}$ hours. Table 3 shows the ranking of 
individual gate returns from the 22 UTC and 23 UTC hours. The wide discrepancy of reflectivity values with range indicates that the reflectivity distributions are drastically different between these two hours, and that we are not sampling the same clutter area locations. There is an approximate empirical relationship of $1 \mathrm{~dB}$ RCA change to $0.1^{\circ}$ elevation angle change, therefore in this case, it was suspected that the antenna elevation increased by about $0.4^{\circ}$. The radar engineer was not initially aware of an antenna elevation change. Subsequently, the engineer confirmed a mechanical failure had occurred and the antenna angle had indeed changed. In this method, the RCA was used as a remote diagnostic tool to inform radar operators of a suspected problem.

\section{b. Practical application of the RCA}

Figures $6 \mathrm{a}$ and $6 \mathrm{~b}$ show timeline traces of the $95^{\text {th }}$ percentile ensemble reflectivity distribution from years 2000-2001, and 2002-2003, respectively. Periods of both radar stability and abrupt change are evident. Some of the abrupt change episodes have been correlated with documented engineering events obtained from KPOL site logs provided by the former on-site contractor 3D Research Corporation. Note that only some of the KPOL engineering logs were available for review and frequently the information lacked sufficient detail, therefore several fluctuations in these timeline analyses are undocumented. These figures confirm that detected sensitivity changes are highly correlated with engineering events. Numerous gross corrections to KPOL reflectivity ( $\geq \pm 2 \mathrm{~dB}$ ) as identified by the RCA method from years 2000 through 2007 are shown in Table 4. Corrections are presented on a monthly scale to provide information on occurrence frequency, however these changes usually do not occur gradually over the course of the month, but typically occur on a more instantaneous scale. Months with two values represent those periods when two distinct fluctuations occurred. Corrections are determined by direct 
comparison of the $95^{\text {th }}$ percentile reflectivity distributions with the established RCA baseline (Figures $6 \mathrm{a}$ and $6 \mathrm{~b}$ ), and are computed as the amounts needed to adjust the $95^{\text {th }}$ percentile to match the established baseline. The RCA method computes calibration adjustments on an hourly and daily basis using data from available volume scans during the period. Hourly RCA values are computed to monitor KPOL stability and to inform radar operators on a near real-time basis as to when significant events occurred. Suspected radar stability issues are diagnosed and discussed in a timely manner with radar operators. Daily RCA values are used as corrections applied in the TSVO operational setting. The TRMM Ground Validation System (GVS) allows for application of calibration corrections through the "Level 1" quality control (QC) algorithm (Kulie et al. 1999, Wolff et al 2005). A QC parameter input file is generated with daily RCA corrections in addition to other adjustable QC parameters based on echo height and reflectivity thresholds. However, before the application of specific calibration corrections, the additional problem of antenna elevation angle change must be addressed. As shown in Figure 5c and Table 3, unexpected changes in KPOL's antenna elevation angle have a pronounced impact on the clutter area reflectivity distributions. Approximate antenna elevation angle changes and their effect on the RCA baseline are shown in Table 5. Those familiar with the history of KPOL operations will not be surprised by the magnitude of the angle changes. The significance of accounting for antenna elevation angle changes is quantified by an interim TSVO product (Version 6), in which RCA corrections were applied at face value without considering antenna irregularities. The consequence is that all RCA fluctuations were considered to be power related, including those associated with antenna elevation angle changes. The resulting approximated power-law $A$ coefficients and $Z_{e}-R$ curves for Version 6 shown in Table 2 and Figure 7 are more divergent than Version 5, and clearly indicate that the inter-annual reflectivity distributions are 
not consistent. The antenna elevation angle had changed multiple times due to a suspected faulty electrical panel, use of a problematic release of a solar tracking utility, elevation drive motor failure, and operator troubleshooting adjustments. To properly account for antenna elevation angle change in RCA methodology, the calibration baseline is shifted by an amount equal to the magnitude of the change in the $95^{\text {th }}$ percentile reflectivity from prior to and following antenna movement. A new calibration baseline is thus established, and this process repeats when the next antenna elevation angle change occurs. For example, if a known antenna angle increase (decrease) of $0.5^{\circ}$ occurred and resulted in an approximate $5 \mathrm{~dB}$ decrease (increase) in the $95^{\text {th }}$ percentile reflectivity distribution, then the RCA baseline would shift down (up) by a corresponding amount ( $5 \mathrm{~dB})$. By shifting the RCA baseline in this manner, there is no change to the quantified calibration correction due to antenna angle.

After adjusting the RCA baseline for antenna elevation angle changes, RCA calibration corrections are applied on a daily basis to adjust KPOL reflectivity to the revised baseline, and instantaneous quality-controlled radar and rain gauge data for entire years are then combined for WPMM distributions for Version 7 (current) product development. Table 2 and Figure 8 show the Version 7 approximated $Z_{e}-R$ power-law $A$ coefficients and yearly WPMM $Z_{e}-R$ curves from years 2000 through 2007 respectively. There is significant improvement in the convergence of the $Z_{e}-R$ curves, and year-to-year agreement in the power-law coefficients. Slight variations in the curves may be related to factors such as the varying quantity of "good" rain gauges used by WPMM (see Amitai, 2000 for combined gauge/radar QC and acceptance/rejection criteria), and the natural variability of rainfall within the scale of a radar pixel. Convergence of the $Z_{e^{-}} R$ curves is a clear indication that relative calibration stability from year-to-year has been significantly improved. 


\section{Comparison with other correction methods}

The research community has recognized the existence of calibration issues with KPOL and has developed other stabilization methods. The TRMM PR has been used as a stable standard for determining ground radar calibration biases (Schumacher and Houze, 2000; A01; Houze et al. 2004). The echo area matching method developed by Schumacher and Houze, 2000 and used in Houze et al. 2004 (hereafter collectively referred to as University of Washington (UW)) determines gross reflectivity calibration offsets by matching echo areas $\geq 17$ $\mathrm{dBZ}$ from the PR and KPOL at the 6-km height level. This method relies on rainy temporal sampling of the PR, and adjusts KPOL calibration offsets (with $\pm 2 \mathrm{~dB}$ uncertainty) so that KPOL echo area has the closest possible match with echo area from the PR. Table 2 from Houze et al. 2004 (not shown) presents calibration corrections from several years, and has good general agreement with RCA determined corrections (Figure 9). Based on PR overpass data, echo area matching, and a sphere calibration performed by NASA staff on-board the NOAA R/V Ron Brown, it was determined that a calibration correction of $+6 \mathrm{~dB}$ was required during the KWAJEX field campaign (Yuter et al. 2005). The RCA method needed an initial calibration baseline, and therefore started with the same adjustment of $+6 \mathrm{~dB}$. Figure 9 shows agreement between UW and RCA methods to within $\pm 1-2 \mathrm{~dB}$ for most time periods, but because echo area matching relies on rainy PR overpasses, significant inter-overpass calibration offsets are missed. January 2001 through August 2001 is a period where the echo area matching method has missed calibration offsets due to the relatively poor temporal sampling of the PR.

A01 also determined ground radar calibration corrections based on comparisons with the TRMM PR. In their study, PR and KPOL (referred to as KWAJEX-S) reflectivities were 
interpolated and statistically matched in a common three-dimensional Cartesian grid. Their data analysis (August to December 1999) of stratiform echo showed a calibration correction of approximately +6 to $+7 \mathrm{~dB}$ needed to be applied to KWAJEX-S. Agreement of calibration corrections from both area echo matching method (UW), and mean reflectivity differences (A01), provides an initial degree of assurance that KPOL was indeed running 'cold' at the beginning of the KWAJEX experiment (August 1999). As in the UW method of area echo matching, the calibration corrections from A01 based on mean reflectivity differences rely on coincident TRMM sampling during rain, and therefore, significant calibration corrections can be missed. In addition, neither UW echo area matching nor A01 mean reflectivity difference methods can detect changes in antenna elevation angle. In contrast, after establishing the initial RCA calibration baseline on August 1, 1999, (50.01 dBZ) the status of KPOL calibration is being closely monitored and calibration offsets are being measured on a continuous hour-by-hour near real-time basis by the RCA method without dependence on PR observations. Section 3 detailed convergence of the TSVO Version 7 WPMM Ze-R reflectivity distributions through coefficients (Table 2) and graphically through the resulting curves (Figure 8). The next section quantifies the improved stability of Version 7 RCA corrected reflectivity over Version 5 through comparison of mean reflectivity differences with the TRMM PR.

\section{Improved Stability of RCA corrected KPOL reflectivity}

It is emphasized that it is not the intention of this paper to validate PR reflectivity measurements, but instead to show improved stability in corrected KPOL reflectivity using the PR as a stable reference; therefore, the fluctuation of the mean differences between instruments is much more important to this study than the absolute magnitude of the differences themselves. 
Readers interested in studies validating TRMM estimates are referred to Datta et al. 1999, Schumacher and Houze, 2000, Nicholson et al. 2003, Fisher, 2004, and Wolff and Fisher, 2008. The multiple panels of Figure 10 show monthly and yearly mean difference (offset) between PR attenuation corrected 2A25 Version 6 stratiform reflectivity and RCA corrected KPOL 2A55 Version 7 stratiform reflectivity for rainy overpasses from years 2000 through 2007 . This is the same type of analysis presented for the Version 5 comparison in section $2 \mathrm{~b}$. Month-to-month fluctuations in mean differences over the eight years are on the order of $\pm 1-2 \mathrm{~dB}$ (with some exceptions). Yearly mean differences fluctuate by approximately $\pm 1 \mathrm{~dB}$ (with 95\%CI bounds within established PR uncertainty), and standard deviations about the mean differences from all yearly observations range from 3.4 to $3.8 \mathrm{~dB}$ (an improvement over the Version 5 standard deviation range of 3.5 to $4.3 \mathrm{~dB}$ ). If measurement uncertainty in RCA corrections is $\pm 0.5 \mathrm{~dB}$, uncertainty in corrected KPOL radar reflectivity is $\pm 1.0 \mathrm{~dB}$, and uncertainty in the PR reflectivity is $\pm 1 \mathrm{~dB}$, then we would expect standard deviations about the mean differences to be within approximately $\pm 2.5 \mathrm{~dB}$. The amount of variability beyond this range is believed to be from factors discussed in Bolan and Chandrasekar, 2003, specifically, time synchronization mismatch between datasets (eight-minute window), geometrical distortion from platform and TRMM attitude perturbations, and possible residual errors in resolution volume matching. However, these sources of error exist in both Version 5 and Version 7 comparisons, and therefore do not significantly affect the intended focus of showing improved KPOL stability. By comparing the Version 5 results (Figure 4) with Version 7 results (Figure 10), significant improvement in stability is shown, especially in years with known calibration issues $(2000,2001$, and 2003). Sample size issues are again a limiting factor in the dry season (Jan-Mar) of each year; therefore comparisons from these months have reduced confidence and are not considered 
reliable. Reviewing year 2003 in closer detail shows an inter-month variability spread in mean differences of $5 \mathrm{~dB}$ in Version 5 ( $+2 \mathrm{~dB}$ in May to $-3 \mathrm{~dB}$ in December), while in Version 7, the inter-month variability spread is approximately $1.5 \mathrm{~dB}(+0.5 \mathrm{~dB}$ in May to $-1 \mathrm{~dB}$ in December). Figure 11 shows Version 5 and Version 7 scatterplots of radar and rain gauge WPMM estimated rainfall from year 2003. In August 2003, the replacement of a directional coupler with an associated loss change resulted in a $+6 \mathrm{~dB}$ increase to the $95^{\text {th }}$ percentile reflectivity distribution (as shown in Figure 6b and Table 4). The Version 5 scatterplot (Figure 11a) depicts the broad uncorrected distribution used to develop the $2003 Z_{e}-R$ lookup table. A key statistic for comparison is the normalized mean absolute deviation (MAD) between radar and rain gauge estimated accumulations, and is defined as

$$
M A D=\frac{\mu_{|G-R|}}{\mu_{G}}
$$

where = statistical average, $G=$ gauge accumulation, and $R=$ radar estimated accumulation. The MAD improves from 0.30 in Version 5 to 0.17 with the RCA corrected Version 7 distribution (Figure 11b), while the correlation ( $r$ ) jumps from 0.59 to 0.71 with the corrected data. In years with significant calibration corrections, the statistical improvement in WPMM distributions is dramatic, as shown in the 2003 example. In years with more subtle calibration changes, the improvement is slight, but still present. Application of the RCA method has imparted significant stability to the reflectivity distributions, which is a requirement for consistent WPMM rain rate estimation. The fluctuations in corrected KPOL reflectivity distributions (Version 7) as compared to the TRMM PR are significantly less than prior version statistics, and are comparable to the established calibration and uncertainty boundaries of the TRMM PR. With the assistance of available radar engineering logs, the RCA technique has 
been retroactively applied to KPOL data from January 2000 through December 2007, effectively salvaging eight years of research data for the science community.

\section{Summary}

The KPOL radar on Kwajalein Island has been designated as a primary ground validation instrument for TRMM. Unfortunately, KPOL has had a long history of calibration and antenna angle uncertainty since the TRMM satellite launch in November 1997. A brief history of KPOL data and historical correction attempts from the GSFC GV program has been presented. The TSVO developed a unique approach, the Relative Calibration Adjustment (RCA) method, to monitor radar sensitivity fluctuations using statistical ensemble characteristics of ground clutter returns. The Version $7 \mathrm{GV}$ reflectivity products (1C51 and 2A55) have been corrected for both calibration and elevation angle errors using the RCA method, which has significantly improved the stability in reflectivity distributions (over Version 5 products) required for WPMM reflectivity - rain rate table development, and for climatological and physical characterization studies. The improved stability is quantified by comparison of mean reflectivity differences with a recognized stable standard, the TRMM PR. The variation of inter-year mean reflectivity differences between the attenuation corrected TRMM PR 2A25 Version 6 reflectivity and TSVO KPOL 2A55 Version 7 reflectivity are on the order of $\pm 1 \mathrm{~dB}$. This is within expected error bounds and comparable to the estimated uncertainty of the PR, while the $95 \% \mathrm{CI}$ bounds of these measurements are within the estimated uncertainty of the PR. Radar - rain gauge accumulation scatterplots have confirmed the improved stability in reflectivity distributions. Therefore, we confidently state that the RCA method has provided the calibration stability needed for significantly improved WPMM rain rate estimation from Kwajalein. The RCA method has 
salvaged over eight years of KPOL data that would otherwise have been unusable, and has provided a remote diagnostic tool to assist data analysts and radar operators in detecting sensitivity and angle changes both historically and in currently observed data. The RCA method may be extensible to other research radars that do not use ground clutter or velocity notch filters prior to data recording. Future research includes investigation of KPOL's dual-polarimetric capability to provide absolute calibration, hydrometeor identification, and rain rate estimation. The RCA method will be used to independently validate calibration adjustments obtained through dual-polarimetric measurements. Version 7 reflectivity and rain rate products are available from the Goddard Earth Sciences Data and Information Services Center (GES DISC http://daac.gsfc.nasa.gov). Further information and near real-time RCA distributions are available from the TRMM Validation site http://trmm-fc.gsfc.nasa.gov/trmm_gv. 


\section{Footnotes}

${ }^{1}$ The radar-measured or effective reflectivity $Z_{e}$ is an average of the distribution of the actual reflectivity $\mathrm{Z}$ of the targets within the volume illuminated by the radar beam, weighted by the beam radiation pattern (Probert-Jones, 1962; Rosenfeld et al. 1992). 


\section{Acknowledgments}

The authors thank Dr. Ramesh Kakar (NASA Headquarters), Mr. Richard Lawrence (Chief, NASA/GSFC TRMM Satellite Validation Office), Dr. Scott Braun (TRMM Project Scientist), and Dr. Robert Adler (former TRMM Project Scientist), for their support of this effort. We thank Dr. David Atlas for his contributions and helpful discussions on RCA theory. We also appreciate the TRMM Precipitation Office support staff, including David Makofski, Bart Kelley, and Marcella (Lynne) Shupp. This research was supported by NASA Grant NNG07EJ50C. 


\section{References}

Amitai, E., D.A. Marks, D.B. Wolff, D.S. Silberstein, B.L. Fisher, and J.L. Pippitt, 2006:

Evaluation of Radar Rainfall Products: Lessons Learned from the NASA TRMM Validation Program in Florida. J. Atmos. Oceanic Technol., 23, 1492-1505.

Amitai, E., 2000: Systematic variation of observed radar reflectivity-rainfall rate relations in the tropics. J. Appl. Meteor. (Special Issue on TRMM), 39, 2198-2208.

Anagnostou, E. N., C. A. Morales, and T. Dinku, 2001: The use of TRMM precipitation radar observations in determining ground radar calibration biases. J. Atmos. Oceanic Technol., 18, 616-628.

Awaka, J., T. Iguchi, H. Kumagai, and K. Okamoto, 1997: Rain type classification algorithm for TRMM precipitation radar. Proc. Int. Geoscience and Remote Sensing Symp., Suntec City, Singapore, Institute of Electrical and Electronics Engineers, 1633-1635.

Blossey, P.N., C.S. Bretherton, J. Cetrone, and M. Kharoutdinov, 2007: Cloud-Resolving Model Simulations of KWAJEX: Model Sensitivities and Comparisons with Satellite and Radar Observations. J. Atmos. Sci., 64, 1488-1508.

Bolen, S. M., and V. Chandrasekar, 2000: Quantitative cross validation of space-based and ground-based radar observations. J. Appl. Meteor., 39, 2071-2079.

Bolen, S. M., and V. Chandrasekar, 2003: Methodology for aligning and comparing spaceborne radar and ground-based radar observations. J. Atmos. Oceanic Technol., 20, 647-659.

Cetrone, J., and R.A. Houze, 2006: Characteristics of Tropical Convection over the Ocean near Kwajalein. Mon. Wea. Rev., 134, 834-853. 
Datta, S., B. Roy, L. Jones, T. Kasparis, P. Ray, and D. Charalampidis, 1999: Evaluation of TRMM precipitation radar rainfall estimates using NEXRAD and rain gauges in central and south Florida. Preprints, $29^{\text {th }}$ Int. Conf. on Radar Meteorology, Montreal, PQ, Canada, Amer. Meteor. Soc., 754-757.

Fisher, B. L., 2004: Climatological validation of TRMM TMI and PR monthly rain products over Oklahoma. J. Appl. Meteor., 43, 519-535.

Holder C, Yuter SE, Sobel A, Aiyyer A, 2008: The mesoscale characteristics of tropical oceanic precipitation during Kelvin and mixed Rossby-gravity wave events. Mon. Wea. Rev.: In Press

Houze, R. A. Jr., S. Brodzik, C. Schumacher, and S. Yuter, 2004: Uncertainties in oceanic radar rain maps at Kwajalein and implications for satellite validation. J. Appl. Meteor., 43, 11141132.

Iguchi, T., T. Kozu, R. Meneghini, J. Awaka, and K. Okamoto, 2000: Rain-profiling algorithm for the TRMM precipitation radar. J. Appl. Meteor., 39, 2038-2052.

Joss, J., and A. Waldvogel, 1967: Ein spectrograph für Niederschlasgstropfen mit automatischer Auswertung (A spectrograph for the automatic analysis of raindrops). Pure Appl. Geophys., 69, 240-246.

Kozu, T., and Coauthors, 2001: Development of precipitation radar onboard the Tropical Rainfall Measuring Mission (TRMM) satellite. IEEE Trans. Geosci. Remote Sens., 39, 102116

Kulie, M. S., M. Robinson, D. A. Marks, B. S. Ferrier, D. Rosenfeld, and D. B. Wolff, 1999: Operational processing of ground validation data for the Tropical Rainfall Measuring 
Mission. Preprints, 29th Int. Conf. on Radar Meteorology, Montreal, QC, Canada, Amer. Meteor. Soc., 736-739.

Kummerow, C., W. Barnes, T. Kozu, J. Shiue, and J. Simpson, 1998: The Tropical Rainfall Measuring Mission (TRMM) sensor package. J. Atmos. Oceanic Technol., 15, 809-817.

Marks, D. A., and Coauthors, 2000: Climatological processing and product development for the TRMM Ground Validation program. Physics and Chemistry of the Earth, (PCE), Part B. Hydrol., Oceans Atmos., 25, 871-876.

Mohr, C. G., and R. L. Vaughan, 1979: An economical procedure for Cartesian interpolation and display of reflectivity factor data in three-dimensional space. J. Appl. Meteor., 18, 661-670.

Nicholson, S.E., B. Some, J. McCollum, E. Nelkin, D. Klotter, Y. Berte, B.M. Diallo, I. Gaye, G. Kpabeba, O. Ndiaye, J.N. Noukpozounkou, M.M. Tanu, A. Thiam, A.A. Toure, and A.K. Traore, 2003: Validation of TRMM and Other Rainfall Estimates with a High-Density Gauge Dataset for West Africa. Part II: Validation of TRMM Rainfall Products. J. Appl. Meteor., 42, 1355-1368.

Probert-Jones, J. R., 1962: The radar equation in meteorology. Quart. J. Roy. Meteor. Soc., 88, 485-495.

Rinehart, R. E., 1978: On the use of ground return targets for radar reflectivity calibration checks. J. Appl. Meteor., 17, 1342-1350.

Rosenfeld, D., D. Atlas, D. B. Wolff, and E. Amitai, 1992: Beamwidth effects on Z-R relations and area-integrated rainfall. J. Appl. Meteor., 31, 454-464.

Rosenfeld, D., D. B. Wolff, and E. Amitai, 1994: The window probability matching method for rainfall measurements with radar. J. Appl. Meteor., 33, 682-693. 
Ryzhkov, A. V., D. Zrnic, and D. Atlas, 1997: Polarimetrically tuned $R(Z)$ relations and comparison of radar rainfall methods. J. Appl. Meteor., 36, 340-349.

Ryzhkov, A. V., S. E. Giangrande, V. M. Melnikov, and T. J. Schuur, 2005: Calibration issues of dual-polarization radar measurements. J. Atmos. Oceanic Technol., 22, 1138-1155.

Schumacher, C., and R. A. Houze, Jr., 2000: Comparison of radar data from the TRMM satellite and Kwajalein oceanic validation site. J. Appl. Meteor., 39, 2151-2164.

Silberstein, D. S., D. B. Wolff, D. A. Marks, D. Atlas, and J. L. Pippitt, 2008: Ground clutter as a monitor of radar stability at Kwajalein, RMI. J. Atmos Oceanic Technol.: In Press.

Sobel, A.H., S.E. Yuter, C.S. Bretherton, and G.N. Kiladis, 2004: Large-Scale Meteorology and Deep Convection during TRMM KWAJEX. Mon. Wea. Rev., 132, 422-444.

Steiner, M., R. A. Houze Jr., and S. E. Yuter, 1995: Climatological characterization of threedimensional storm structure from operational radar and rain gauge data. J. Appl. Meteor., 34, 1978-2007.

Straka, J. M., D. S. Zrnic, and A. V. Ryzhkov, 2000: Bulk hydrometeor classification and quantification using polarimetric radar data: synthesis of relations. J. Appl. Meteor., 39, $1341-1372$.

Tokay, A., D. B. Wolff, D. A. Marks, and T. Kasparis, 2008a: Raindrop size distribution measurements in Florida and Kwajalein. Third International TRMM Science Conference, NASA JAXA, Las Vegas, NV Feb. 4-8, 2008.

Tokay, A., P. G. Bashor, E. Habib, and T. Kasparis, 2008b: Raindrop size distribution measurements in tropical cyclones. Mon. Wea. Rev., 136, 1669-1685. 
Ulbrich, C. W., and L. G. Lee, 1999: Rainfall measurement error by WSR-88D radars due to variations in Z-R law parameters and the radar constant. J. Atmos. Oceanic Technol., 16, 1017-1024.

Vivekanandan, J., G. Zhang, S. M. Ellis, D. Rajopadhyaya, and S. A. Avery, 2003: Radar reflectivity calibration using differential propagation phase measurement. Radio Sci., 38(3), 8049, doi:10.1029/2002RS002676.

Wang, J., B. L. Fisher, and D. B. Wolff, 2008: Estimating rain rates from tipping-bucket rain gauge measurements. J. Atmos. Oceanic Technol., 25, 43-56.

Wilks, D. S., 1995: Statistical Methods in the Atmospheric Sciences. First Edition, Academic Press, $467 \mathrm{pp}$.

Wolff, D. B., D. A. Marks, E. Amitai, D. S. Silberstein, B. L. Fisher, A. Tokay, J. Wang, and J. L. Pippitt, 2005: Ground Validation for the Tropical Rainfall Measuring Mission (TRMM). J. Atmos. Oceanic Technol., 22, 365-379.

Wolff, D. B., and B. L. Fisher, 2008: Comparisons of instantaneous TRMM ground validation and satellite rain rate estimates at different spatial scales. J. Climate Appl. Meteor. (in press).

Yuter, S. E., R. A. Houze, Jr., E. A. Smith, T. Wilheit, and E. Zipser, 2005: Physical characterization of tropical oceanic convection observed in KWAJEX. J. Appl. Meteor., 44, $385-415$. 


\section{List of Figure Captions}

Figure 1 The location of Kwajalein Island in the Republic of the Marshall Islands (from Wolff et al. 2005). The KPOL S-band radar is located at the center of the image. Rain gauge locations from the KWA network are shown as black squares.

Figure 2 TSVO GV Version 5 WPMM yearly $Z_{\mathrm{e}}-\mathrm{R}$ curves from 2000-2007. Divergence in $Z_{e}-R$ curves signifies that relative stability in reflectivity distributions from year-to-year does not exist.

Figure 3 Composite raindrop spectra at $40 \mathrm{dBZ}$ (a) from four rain events in two different years in Kwajalein and (b) from three events in Roi-Namur. The number of oneminute disdrometer observations in each rain event is given. The disdrometer calculated total number of drops, liquid water content, and rain rate are also given for each rain event.

Figure 4 Monthly and yearly comparison of mean reflectivity difference (offset) between the TRMM PR (2A25 -Version 6) and TSVO KPOL (2A55 - Version 5) from years 2000 through 2007. The final column in each panel is for the entire year. Increased offsets in January through March of each year are related to limited sample size in the dry season. 
Figure 5 Hourly and daily PDF/CDF plots of clutter area reflectivity showing distinction between a stable calibration day, a problem calibration day, and an antenna elevation irregularity day. Each curve is color-coded by hour, and the ensemble or daily curve is shown by the bold red line. The RCA values, which represent the difference (in $\mathrm{dB}$ ) between the current calibration from the baseline (set on 1 August 1999), are shown. The $95^{\text {th }}$ percentile reflectivity is indicated by the intersection of the two dotted black lines, and "counts" represents the number of reflectivity points in the daily distribution. (a) Distributions from a stable calibration day with hour-to-hour fluctuation in RCA amounts less than $0.5 \mathrm{~dB}$. Note the convergence in hourly PDFs and CDFs at the $95^{\text {th }}$ percentile. (b) Distributions from a problem calibration day with RCA values significantly changing from the 0 UTC hour to 3 UTC hour. Note the divergence in hourly PDFs and CDFs at the $95^{\text {th }}$ percentile. (c) Distributions from an antenna elevation irregularity day showing a significant fluctuation in hourly RCA values from the 22 UTC to 23 UTC hours, and divergence in hourly and daily distributions at the $95^{\text {th }}$ percentile. Radar operators were notified of this RCA detected irregularity, and subsequently discovered a mechanical failure in the antenna hardware that caused an excessive beam overshoot.

Figure 6 Timeline of the correlation between the $95^{\text {th }}$ percentile of ground clutter pixels and documented KPOL engineering events for years (a) 2000 and 2001, and (b) 2002 and 2003. The bold horizontal line near $50 \mathrm{dBZ}$ represents the calibration baseline. PFN is the pulse forming network. Due to lack of information, some fluctuations are undocumented. 
Figure 7 TSVO GV Version 6 WPMM yearly Ze-R curves from 2000-2007. Version 6 curves have RCA corrections applied. All corrections were considered to be related to power calibration. The divergence in curves shows the effect of antenna elevation change on the clutter area reflectivity distributions.

Figure 8 TSVO GV Version 7 WPMM yearly $Z_{\mathrm{e}}-\mathrm{R}$ curves from 2000-2007. Version 7 curves have both RCA and antenna elevation angle corrections applied. Convergence in the $Z_{\mathrm{e}}-\mathrm{R}$ curves is the expected result, and signifies that WPMM is using stable reflectivity distributions. Minor year-to-year curve variation may be due to the natural variability of rainfall.

Figure 9 Comparison between RCA and the University of Washington (UW) calibration offsets (from Silberstein et al. 2008). The RCA method is based on using KPOL ground clutter returns to determine calibration offsets, while the UW method uses echo area matching between the TRMM PR and KPOL. Agreement is generally within $\pm 1-2 \mathrm{~dB}$, however calibration fluctuations are missed by the echo area matching method due to the temporal sampling of the PR.

Figure 10 Monthly and yearly comparison of mean reflectivity difference (offset) between the TRMM PR (2A25 -Version 6) and TSVO KPOL (2A55 - Version 7) from years 2000 through 2007. The final column in each panel is for the entire year. Increased offsets in January through March of each year are related to limited sample size in the dry season.

Figure 11 Version 5 and Version 7 yearly scatterplots of radar and rain gauge WPMM estimated rainfall from year 2003. To increase sample size and provide robust statistics, data are compiled on a monthly basis and combined for yearly plots. 
TSP 3A54 is the monthly rainfall estimate from the radar using the WPMM derived $Z_{e}-R$ lookup table from 2003. The monthly rain gauge data (TSP 2A56) are dependent, therefore, radar-to-gauge $(\mathrm{R} / \mathrm{G})$ accumulation ratio is near unity. $\mathrm{N}_{\mathrm{p}}$ represents the total number of monthly points (rain gauges) used in the analysis. The dashed line in each panel is a one-to-one correspondence line, while the solid lines represent a least-squares fit regression. (a) A significant calibration event occurred on 19 August 2003 with the replacement of a directional coupler (see Figure 5b), and resulted in a broad reflectivity distribution for WPMM matching. This is reflected in the mean absolute deviation (MAD) and correlation (r) statistics. (b) After RCA correction, the consistency of the reflectivity distribution for WPMM matching has significantly improved as shown by the statistics and reduced scatter. 


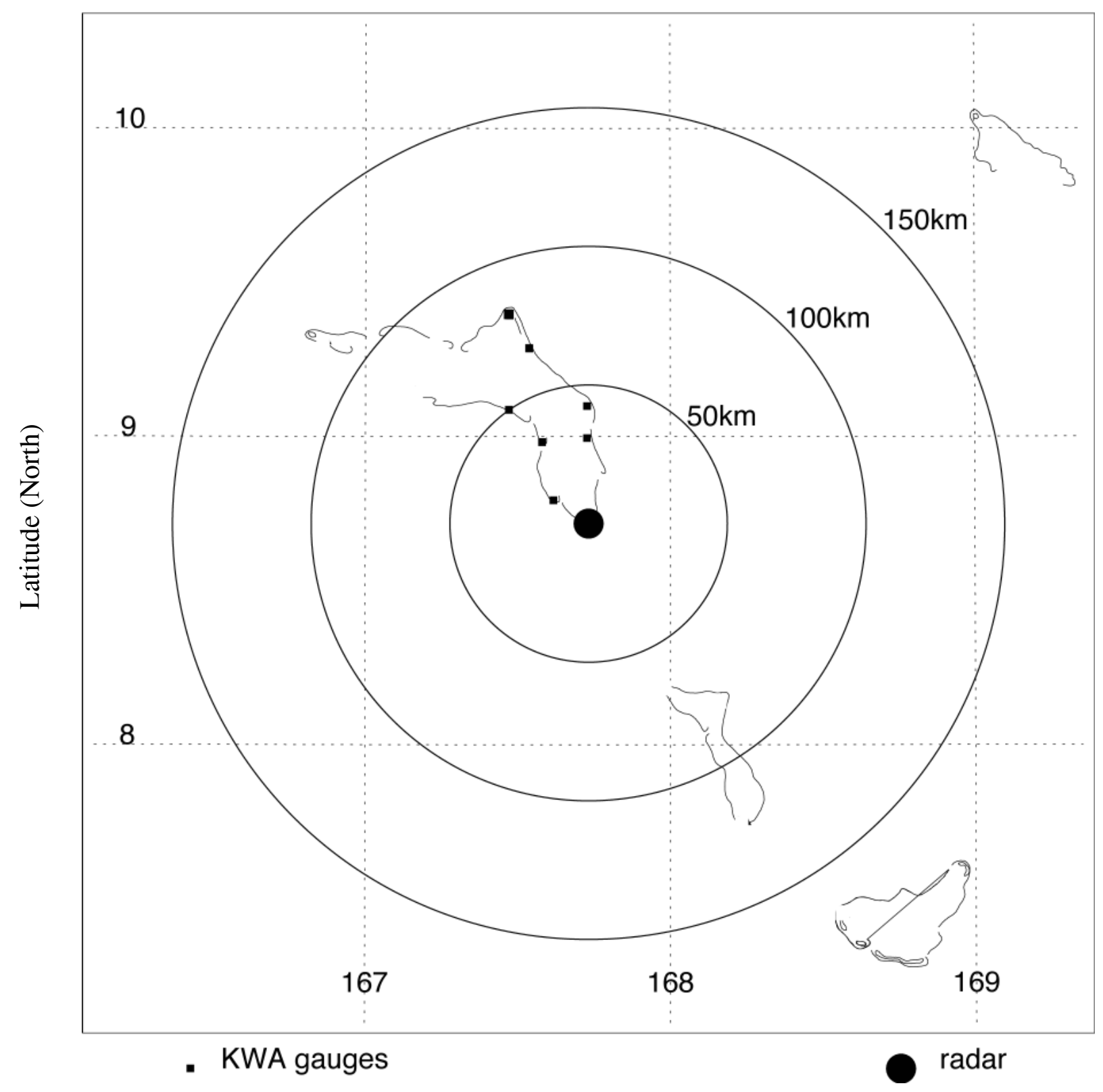

Longitude (East)

Figure 1 The location of Kwajalein Island in the Republic of the Marshall Islands (from Wolff et al. 2005). The KPOL S-band radar is located at the center of the image. Rain gauge locations from the KWA network are shown as black squares. 


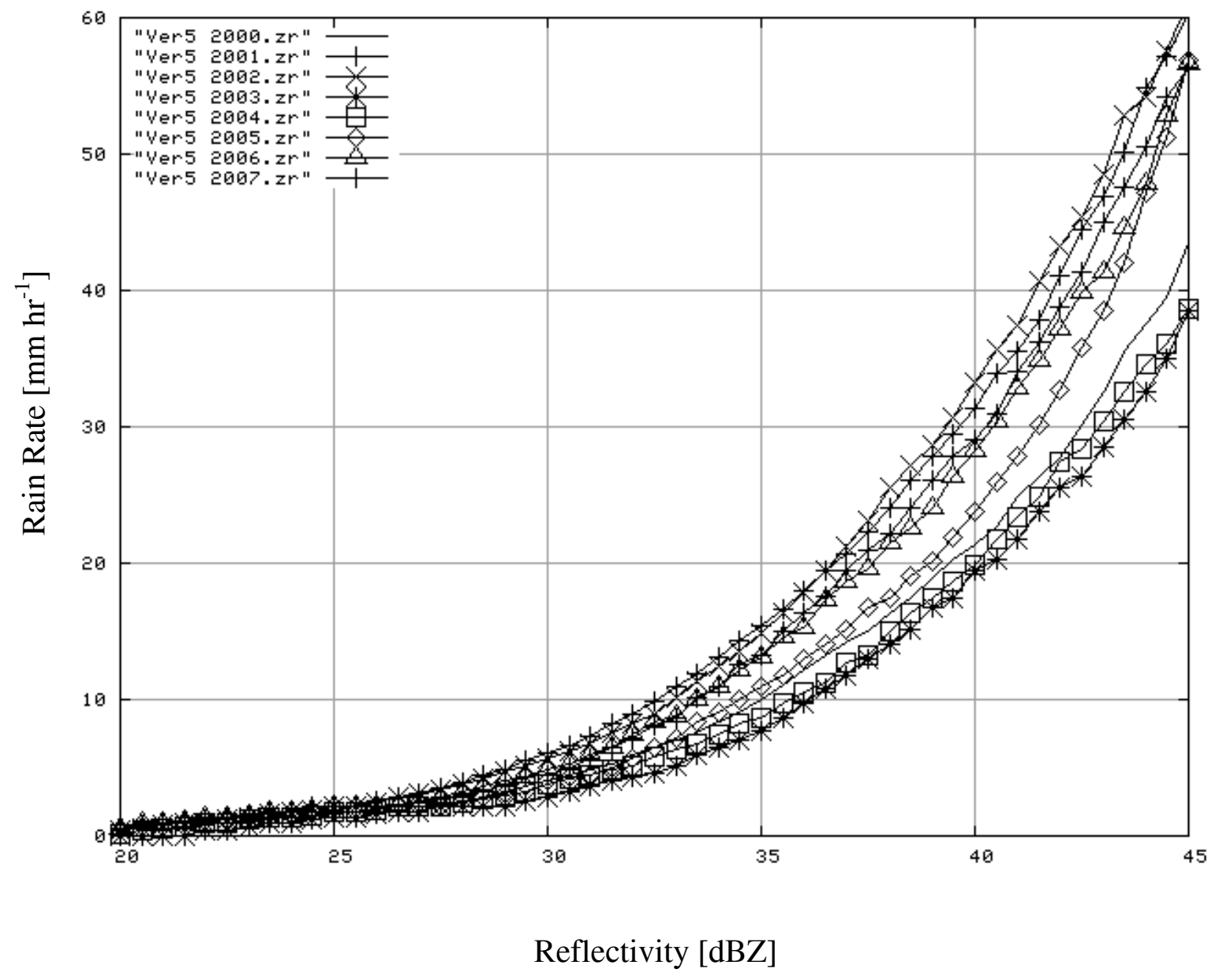

Figure 2. TSVO GV Version 5 WPMM yearly $Z_{e^{-}} R$ curves from 2000-2007. Divergence in $Z_{e^{-}} R$ curves signifies that relative stability in reflectivity distributions from year-to-year does not exist. 

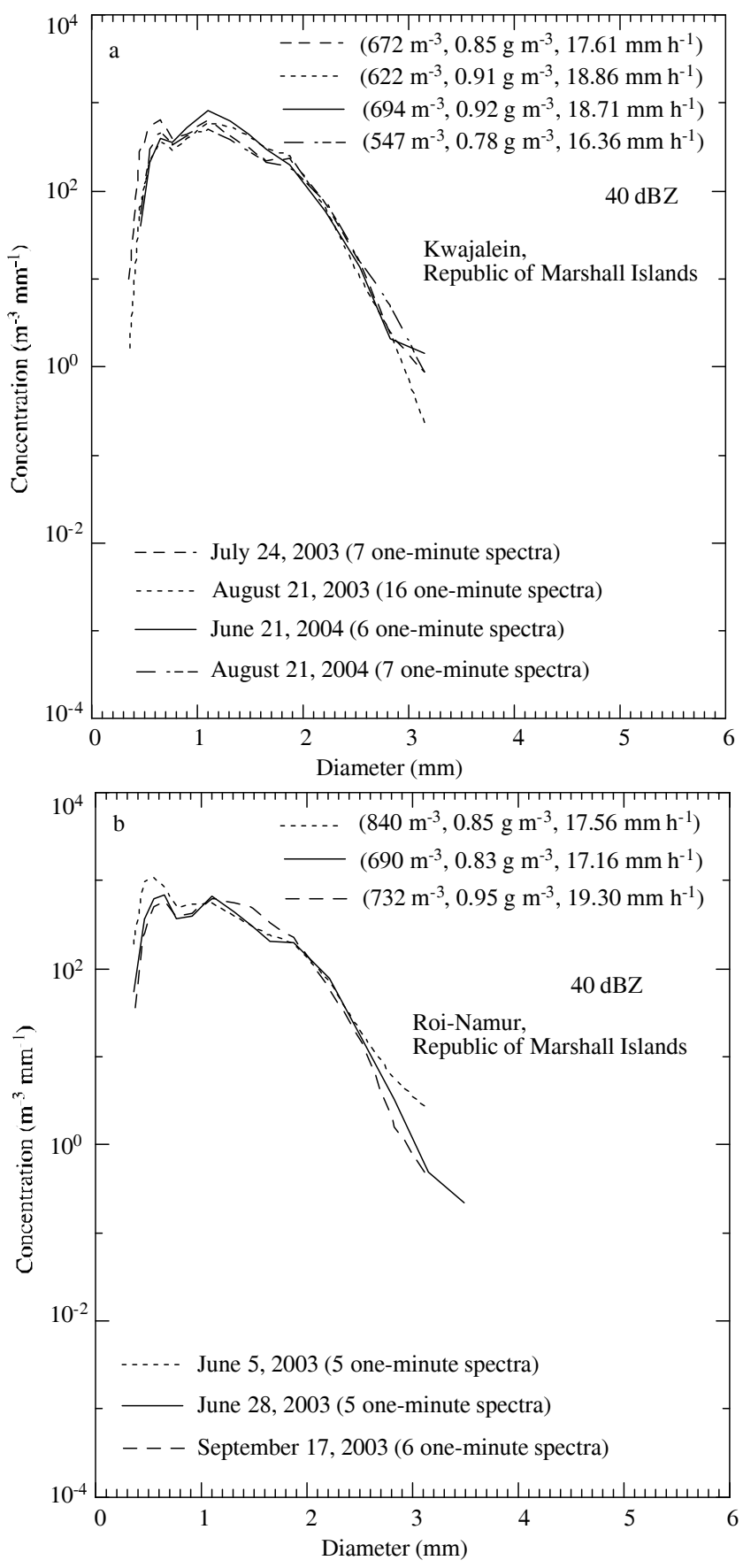

Figure 3. Composite raindrop spectra at $40 \mathrm{dBZ}$ (a) from four rain events in two different years in Kwajalein and (b) from three events in Roi-Namur. The number of one-minute disdrometer observations in each rain event is given. The disdrometer calculated total number of drops, liquid water content, and rain rate are also given for each rain event. 


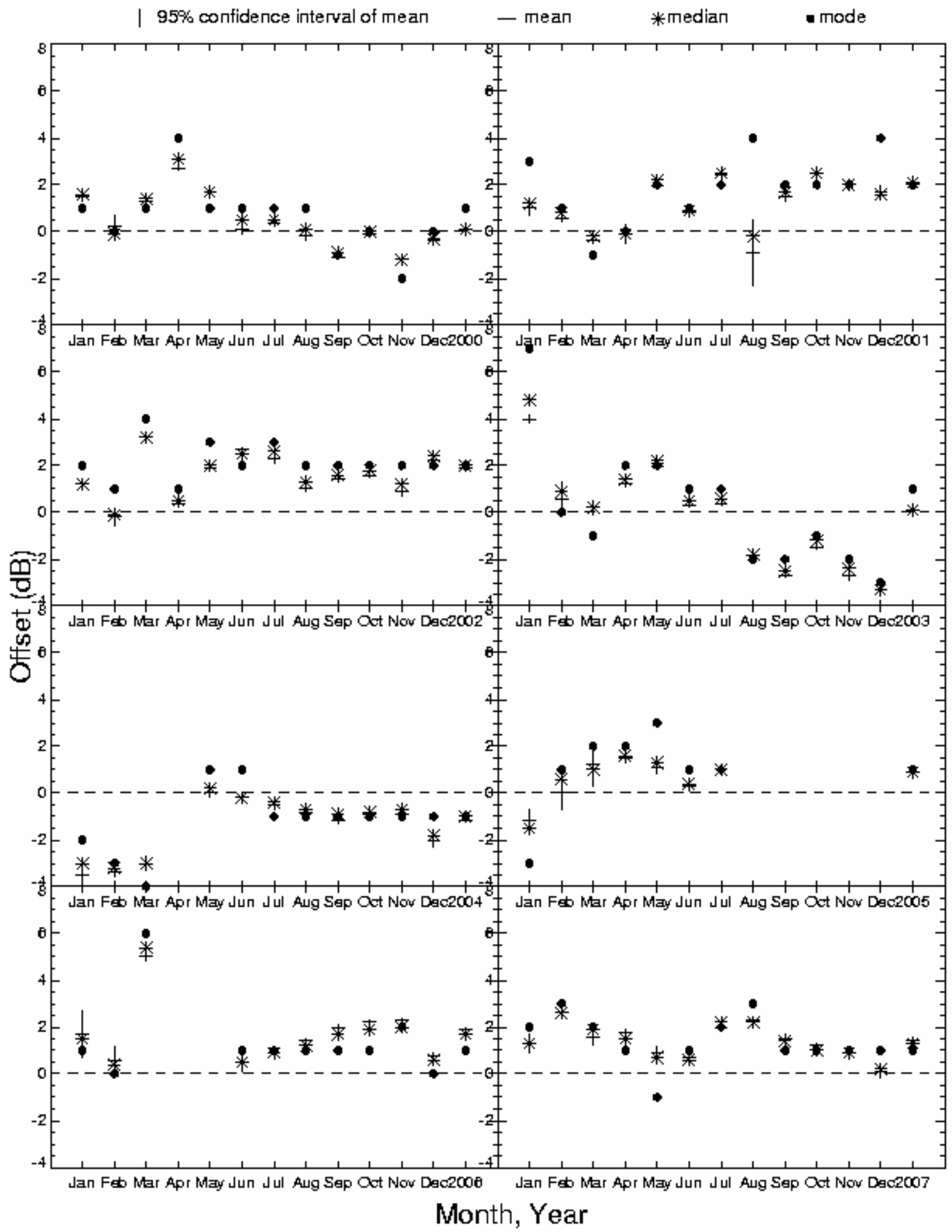

Figure 4 Monthly and yearly comparison of mean reflectivity difference (offset) between the TRMM PR (2A25 -Version 6) and TSVO KPOL (2A55 - Version 5) from years 2000 through 2007. The final column in each panel is for the entire year. Increased offsets in January through March of each year are related to limited sample size in the dry season. 

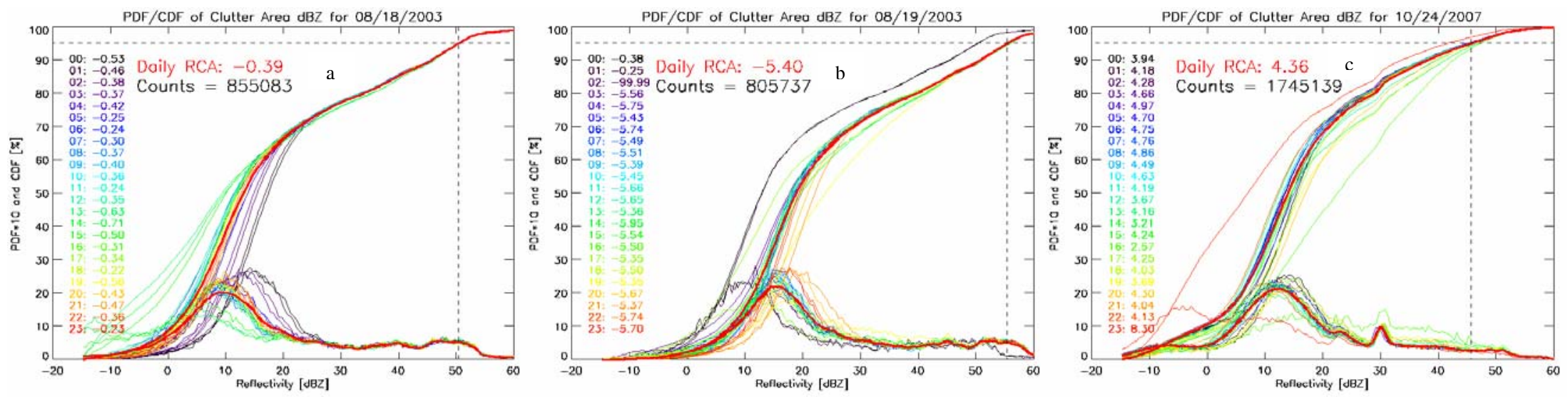

Figure 5 Hourly and daily PDF/CDF plots of clutter area reflectivity showing distinction between a stable calibration day, a problem calibration day, and an antenna elevation irregularity day. Each curve is color-coded by hour, and the ensemble or daily curve is shown by the bold red line. The RCA values, which represent the difference (in $\mathrm{dB}$ ) between the current calibration from the baseline (set on 1 August 1999), are shown. The $95^{\text {th }}$ percentile reflectivity is indicated by the intersection of the two dotted black lines, and "counts" represents the number of reflectivity points in the daily distribution. (a) Distributions from a stable calibration day with hour-to-hour fluctuation in RCA amounts less than $0.5 \mathrm{~dB}$. Note the convergence in hourly PDFs and CDFs at the $95^{\text {th }}$ percentile. (b) Distributions from a problem calibration day with RCA values significantly changing from the 0 UTC hour to 3 UTC hour. Note the divergence in hourly PDFs and CDFs at the $95^{\text {th }}$ percentile. (c) Distributions from an antenna elevation irregularity day showing a significant fluctuation in hourly RCA values from the 22 UTC to 23 UTC hours, and divergence in hourly and daily distributions at the $95^{\text {th }}$ percentile. Radar operators were notified of this RCA detected irregularity, and subsequently discovered a mechanical failure in the antenna hardware that caused an excessive beam overshoot. 


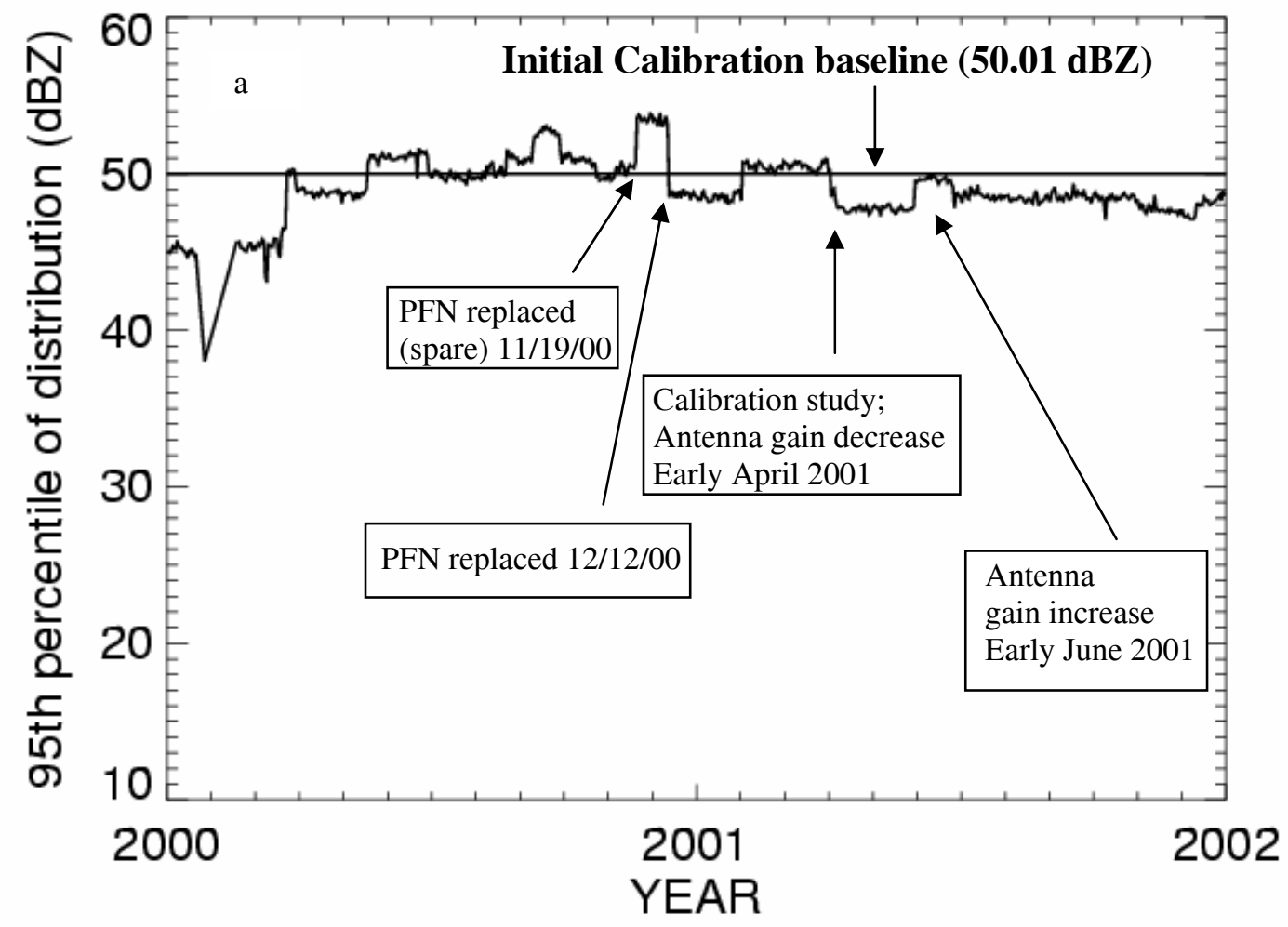

Figure 6a. Timeline of the correlation between the $95^{\text {th }}$ percentile of ground clutter pixels and documented KPOL engineering events for years 2000 and 2001. The bold horizontal line near $50 \mathrm{dBZ}$ represents the calibration baseline. PFN is the pulse forming network. Due to lack of information, some fluctuations are undocumented. 


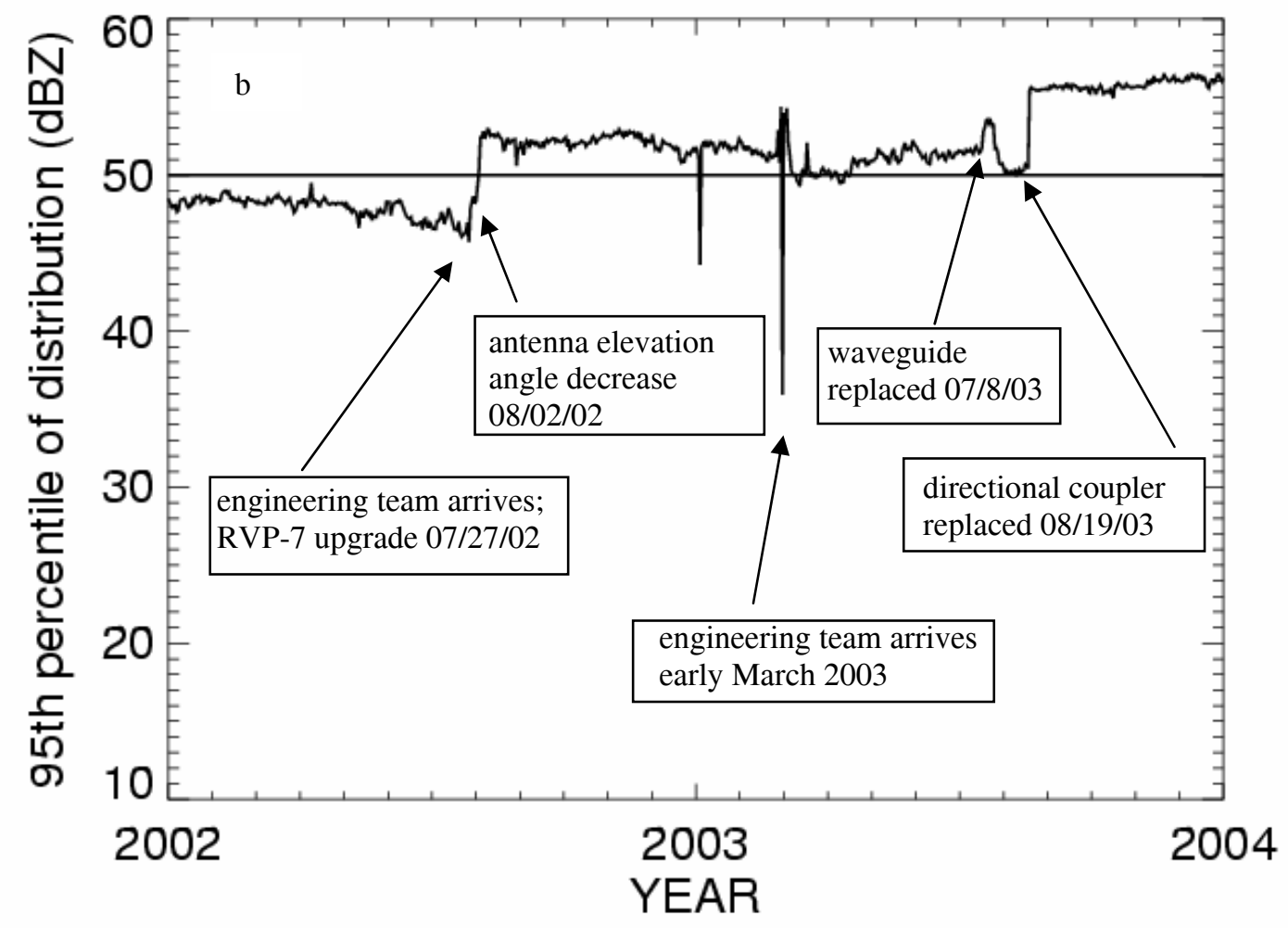

Figure $6 \mathrm{~b}$. Timeline of the correlation between the $95^{\text {th }}$ percentile of ground clutter pixels and documented KPOL engineering events for years 2002 and 2003. The bold horizontal line near $50 \mathrm{dBZ}$ represents the calibration baseline. Due to lack of information, some fluctuations are undocumented. 


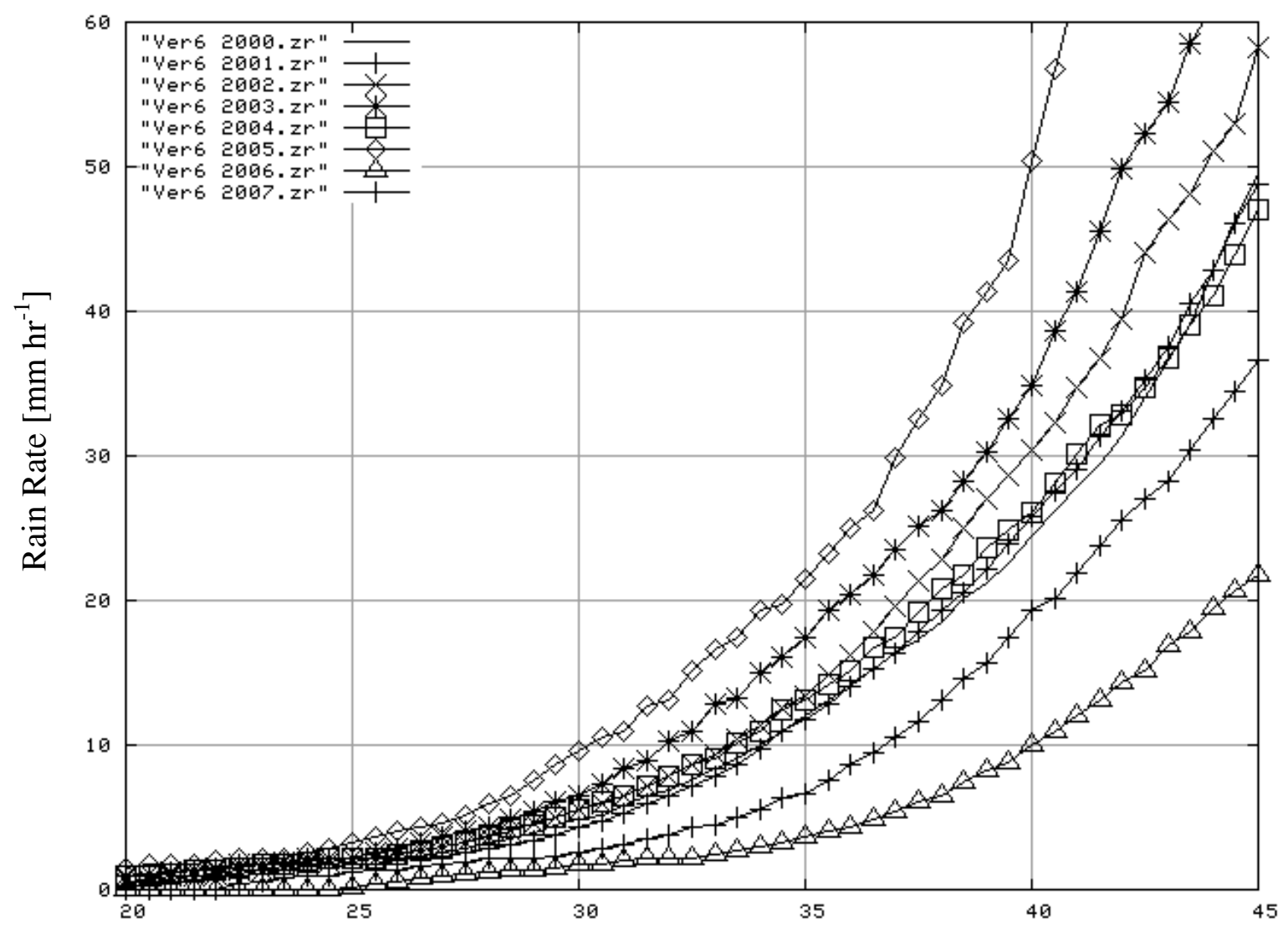

Reflectivity [dBZ]

Figure 7. TSVO GV Version 6 WPMM yearly Ze-R curves from 2000-2007. Version 6 curves have RCA corrections applied. All corrections were considered to be related to power calibration. The divergence in curves shows the effect of antenna elevation change on the clutter area reflectivity distributions. 


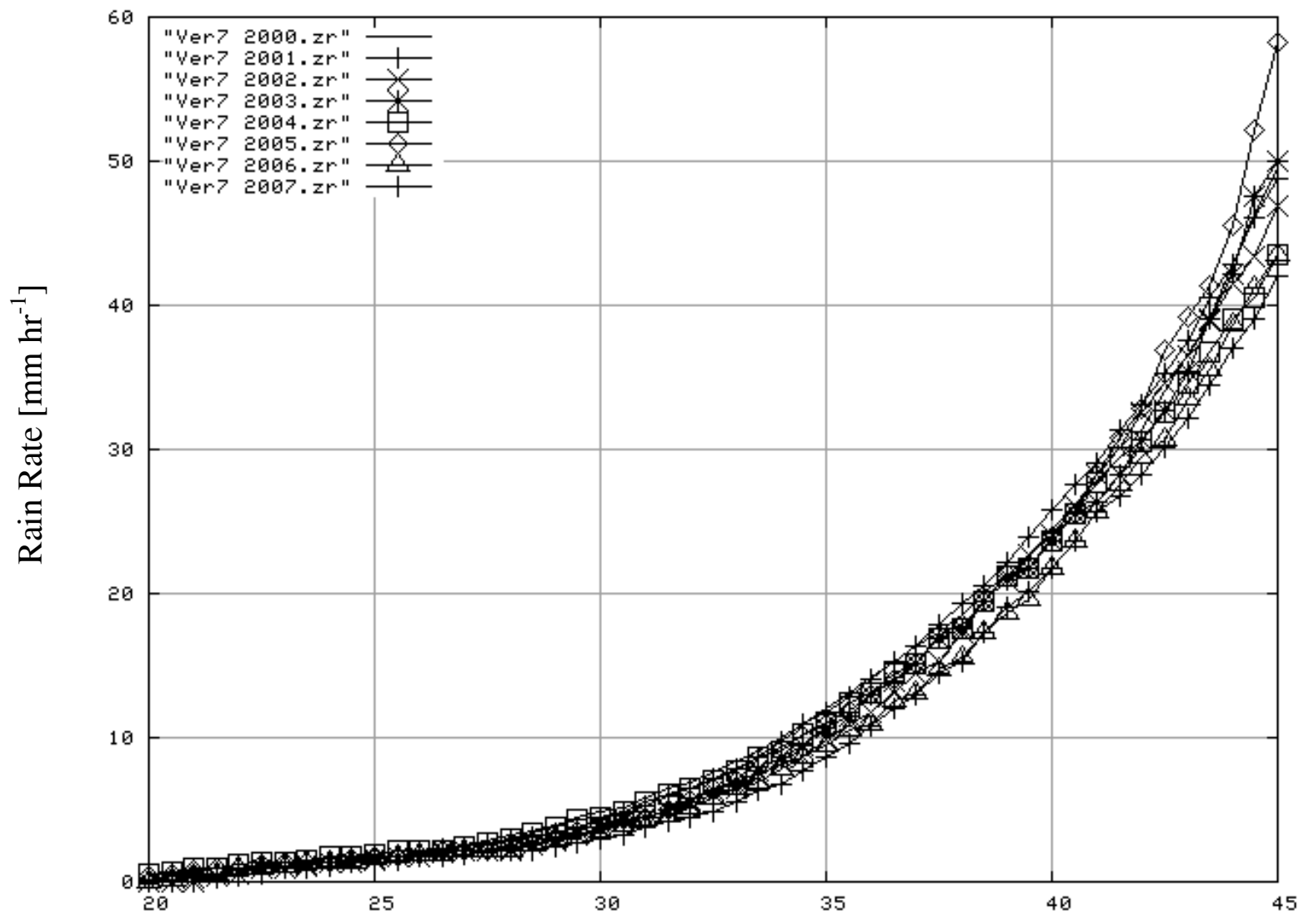

Reflectivity [dBZ]

Figure $8 \quad$ TSVO GV Version 7 WPMM yearly $Z_{\mathrm{e}}-\mathrm{R}$ curves from 2000-2007. Version 7 curves have both RCA and antenna elevation angle corrections applied. Convergence in the $Z_{e}-R$ curves is the expected result, and signifies that WPMM is using stable reflectivity distributions. Minor year-to-year curve variation may be due to the natural variability of rainfall. 


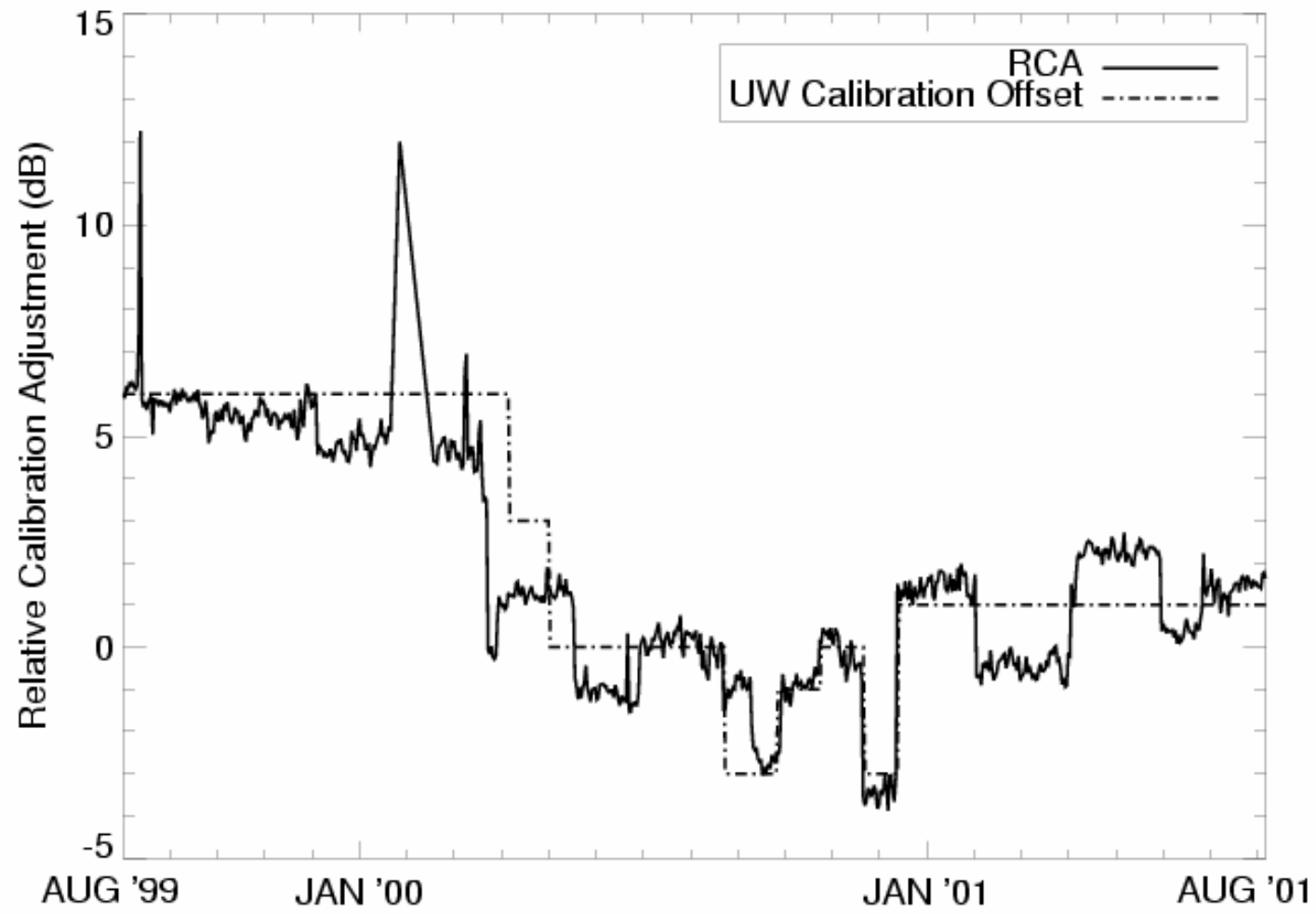

Figure 9. Comparison between RCA and the University of Washington (UW) calibration offsets (from Silberstein et al. 2008). The RCA method is based on using KPOL ground clutter returns to determine calibration offsets, while the UW method uses echo area matching between the TRMM PR and KPOL. Agreement is generally within $\pm 1-2 \mathrm{~dB}$, however calibration fluctuations are missed by the echo area matching method due to the temporal sampling of the PR. 


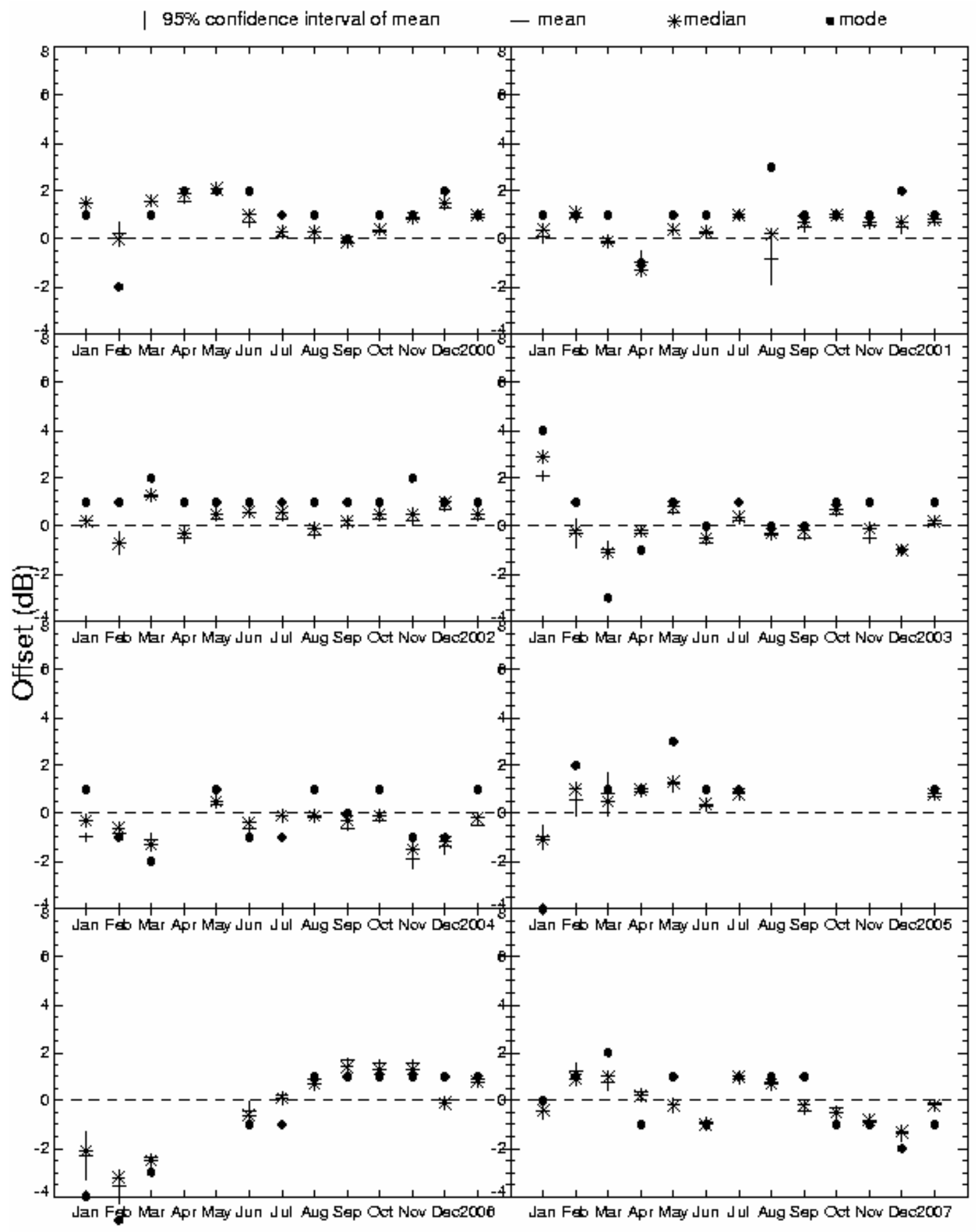

Figure 10 Monthly and yearly comparison of mean reflectivity difference (offset) between the TRMM PR (2A25 -Version 6) and TSVO GV (2A55 - Version 7) from years 2000 through 2007. The final column in each panel is for the entire year. Increased offsets in January through March of each year are related to limited sample size in the dry season. 

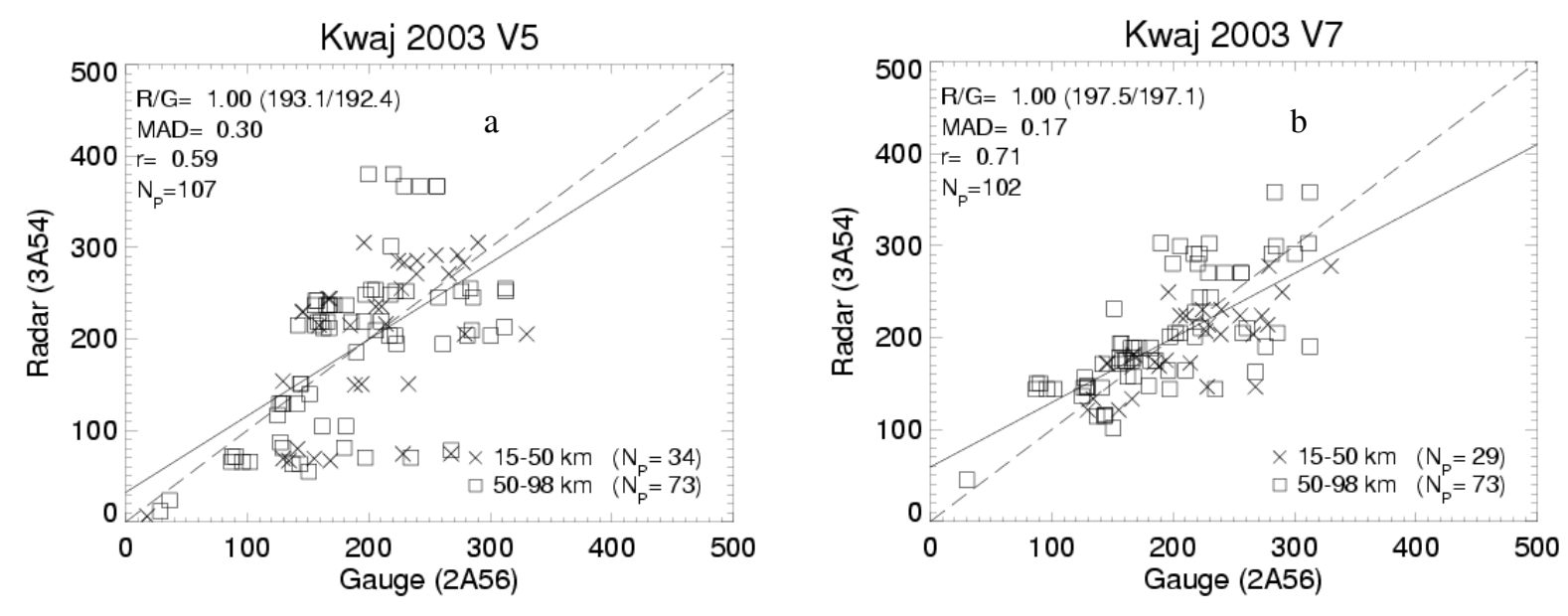

Figure 11 Version 5 and Version 7 yearly scatterplots of radar and rain gauge WPMM estimated rainfall from year 2003. To increase sample size and provide robust statistics, data are compiled on a monthly basis and combined for yearly plots. TSP 3A54 is the monthly rainfall estimate from the radar using the WPMM derived $Z_{e}-R$ lookup table from 2003 . The monthly rain gauge data (TSP 2A56) are dependent, therefore, radar-to-gauge (R/G) accumulation ratio is near unity. $\mathrm{N}_{\mathrm{p}}$ represents the total number of monthly points (rain gauges) used in the analysis. The dashed line in each panel is a one-to-one correspondence line, while the solid lines represent a least-squares fit regression. (a) A significant calibration event occurred on 19 August 2003 with the replacement of a directional coupler (see Figure 6b), and resulted in a broad reflectivity distribution for WPMM matching. This is reflected in the mean absolute deviation (MAD) and correlation (r) statistics. (b) After RCA correction, the consistency of the reflectivity distribution for WPMM matching has significantly improved as shown by the statistics and reduced scatter. 
Table 1. Task configuration of the KPOL radar. Columns are task name, radar polarization, elevation angles (deg), and pulse repetition frequency (PRF). The volume scans alternate between $\mathrm{A}$ and $\mathrm{B}$, with one surveillance scan between volume scan sets. Volume and surveillance scan completion times are 5:25 (min:sec) and 0:53, respectively. There are 10 volume scans per hour (5-A scans and 5-B scans) and 240 total volume scans per day (if 100\% operational).

\begin{tabular}{llcr} 
Task & Polarization & Elevation Angles & PRF \\
\hline GVVOL_A & Dual & $0.4,1.4,2.3,4.2,6.1,8.0,9.9,11.8,14.0,16.6,19.6,23.2$ & 960 \\
GVVOL_B & Dual & $0.4,1.4,3.3,5.2,7.1,9.0,10.9,12.9,15.2,18.0,21.3,25.3960$ \\
Surv_TRMM & Horizontal & 0.4 &
\end{tabular}


Table 2: Approximated $Z_{e^{-}} R$ power-law ' $A$ ' coefficients by year and TSVO GV product version number. V5 coefficients have no calibration or elevation corrections applied. V6 coefficients have calibration adjustments applied but no accounting for changes in antenna elevation. V7 coefficients incorporate both RCA and correctly applied elevation adjustments. The yearly coefficients show much better agreement in Version 7, providing further evidence that statistical consistency has been improved. In all versions and years, the exponent of the power-law approximation is 1.4 .

\begin{tabular}{lccc} 
Year/Version & V5 & V6 & V7 \\
\hline 2000 & 158 & 129 & 129 \\
2001 & 92 & 132 & 132 \\
2002 & 95 & 101 & 155 \\
2003 & 204 & 76 & 147 \\
2004 & 172 & 108 & 132 \\
2005 & 136 & 50 & 135 \\
2006 & 111 & 512 & 168 \\
2007 & 110 & 231 & 180
\end{tabular}


Table 3. Ranking of gates in order of descending reflectivity magnitude to diagnose antenna elevation angle irregularity. The reflectivity distribution from the 15 most intense reflectivity gates from 2208 UTC (hourly RCA value of $4.1 \mathrm{~dB}$ ) is substantially different from the top 15 gates from 2348 UTC (RCA value of $8.3 \mathrm{~dB}$ ). Reflectivity gates are of lower intensity in the 23 UTC hour, and the distances from the radar are much closer. The maximum range from the radar during the 22 UTC hour is $15.8 \mathrm{~km}$, and the lowest range is $1.6 \mathrm{~km}$. However during the 23 UTC hour, the maximum range is $1.6 \mathrm{~km}$, while the lowest range is less than $1 \mathrm{~km}$. The decreased reflectivity magnitude and closer distances in the 23 UTC hour indicate that the antenna elevation angle has increased, and clutter targets at farther range are being overshot.

24 October 2007: 2208 UTC 24 October 2007: 2348 UTC

\begin{tabular}{crrrrrr} 
Rank & $Z_{e}(d B Z)$ & Azimuth $\left({ }^{\circ}\right)$ & Dist $(\mathrm{km})$ & $Z_{e}(d B Z)$ & Azimuth $\left(^{\circ}\right)$ & Dist $(\mathrm{km})$ \\
\hline 1 & 62.5 & 305 & 15.8 & 58.5 & 31 & 1.2 \\
2 & 62.0 & 303 & 5.0 & 58.0 & 28 & 1.2 \\
3 & 61.5 & 3 & 6.4 & 57.5 & 293 & 1.2 \\
& & & & & & \\
4 & 60.5 & 305 & 14.2 & 57.5 & 292 & 1.2 \\
5 & 60.5 & 295 & 1.6 & 57.5 & 32 & 1.2 \\
6 & 60.5 & 294 & 1.6 & 57.5 & 28 & 1.0 \\
7 & 60.5 & 3 & 6.2 & 57.5 & 27 & 1.0 \\
8 & 60.0 & 305 & 15.6 & 56.5 & 294 & 1.6 \\
9 & 60.0 & 292 & 1.6 & 56.5 & 294 & 1.0 \\
& & & & & & \\
10 & 59.5 & 306 & 14.2 & 56.5 & 34 & 0.8 \\
11 & 59.5 & 4 & 6.2 & 56.5 & 29 & 1.0 \\
12 & 59.0 & 298 & 1.6 & 56.0 & 294 & 1.2 \\
13 & 59.0 & 297 & 1.6 & 55.5 & 298 & 1.6 \\
15 & 59.0 & 32 & 1.2 & 55.0 & 295 & 1.2 \\
& 59.0 & 31 & 1.2 & 55.0 & 33 & 0.8
\end{tabular}


Table 4: Significant KPOL sensitivity fluctuations (approximate) for years 2000 through 2007 as detected by the RCA method. Calibration corrections (dB) are relative to the initial established baseline (50 dBZ). Dates with two values represent those months when two distinct fluctuations occurred. Radar events were corroborated with site engineering logs when available. The 2005 cascade failure data were not salvageable.

\begin{tabular}{lll} 
Date Cal. Correction $(\mathrm{dB})$ & Reason \\
\hline March 2000 & +6 & annual calibration study - many changes \\
May 2000 & +3 & unknown \\
June 2000 & -2 & unknown \\
August 2000 & +2 & pulse forming network (PFN) replaced \\
September 2000 & $+3,-2$ & unknown \\
November 2000 & +4 & PFN replacement \\
December 2000 & -6 & PFN replacement \\
February 2001 & +3 & unknown \\
April 2001 & -4 & annual calibration study \\
June 2001 & $+3,-2$ & antenna gain changes / unknown \\
July 2002 & +2 & waveguide replacement \\
July 2003 & $+2,-3$ & waveguide replacement \\
August 2003 & +6 & replaced directional coupler \& loss change \\
April 2004 & -9 & annual calibration study (power + elevation angle) \\
May 2004 & +4 & change to directional coupler loss \\
July-December 2005 & $>10$ & KPOL very unstable - cascade failure \\
January-December 2006 & None & \\
February 2007 & $+2,-2$ & RCA sensitivity testing and validation \\
March 2007 & +2 & computer systems upgrade
\end{tabular}


Table 5: RCA baseline changes due to variation in antenna elevation angle. Baseline change was determined by change in $95^{\text {th }}$ percentile reflectivity distribution.

\begin{tabular}{lcl} 
Date & Baseline $(\mathrm{dB})$ & Comment \\
\hline August 1999 & 50.01 & initial KWAJEX established baseline \\
August 2002 & 54.07 & antenna elevation decrease $\left(\sim 0.41^{\circ}\right)$ \\
March 2003 & 52.82 & antenna elevation increase $\left(\sim 0.12^{\circ}\right)$ \\
August 2004 & 54.24 & antenna elevation decrease $\left(\sim 0.14^{\circ}\right)$ \\
January 2006 & 48.04 & antenna elevation increase $\left(\sim 0.62^{\circ}\right)$ \\
June 2006 & 45.14 & antenna elevation increase $\left(\sim 0.29^{\circ}\right)$
\end{tabular}

